\title{
Chemical tools for modulating autophagy
}

\author{
Gemma Triola \\ Institute of Advanced Chemistry of Catalonia (IQAC), Spanish Research Council \\ (CSIC), Jordi Girona 18-26, Barcelona, Spain \\ Phone number +34 934006100; Fax: +34 932045904; email: \\ gemma.triola@iqac.csic.es
}

Graphical abstract

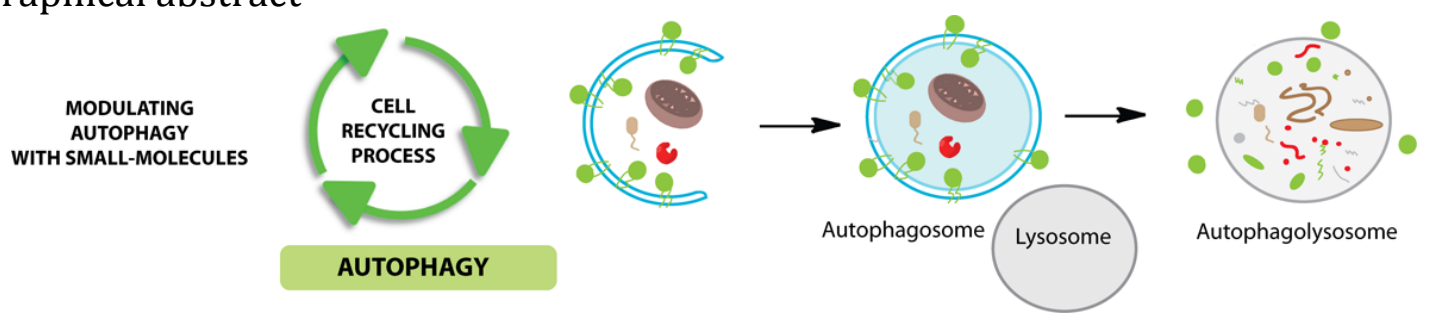

\begin{abstract}
Cells employ autophagy to recycle unneeded or damaged material and this process is crucial to keep cellular homeostasis. Consequently, excessive or insufficient autophagy levels can be deleterious for the cells and are strongly related with diseases such as cancer and neurodegenerative disorders, respectively. Many efforts have been done in the last decade to elucidate the mechanisms regulating autophagy. These studies have enabled the in-depth characterization of new targets that have been employed to design and identify novel autophagy modulators of great interest as potential therapeutic agents. In this report an overview will be given of the different autophagy-related targets as well as of the compound classes that have been identified, designed and synthesized to modulate this cellular process.
\end{abstract}

\section{Introduction}

Autophagy (or self-eating) is a cellular pathway that regulates the lysosomal degradation and recycling of obsolete organelles, long-lived proteins, protein aggregates and pathogens. This process occurs under basal conditions and has a crucial role in cellular development, differentiation, survival and homeostasis. ${ }^{1}$

Three different pathways can be used for this purpose: the chaperone-mediated autophagy (CMA), microautophagy and macroautophagy. In the chaperonemediated autophagy, cytosolic proteins to be degraded are specifically selected by chaperones such as Hsc70 that recognize a pentapeptide in their sequence (KFERQ-like) and by doing so target them to the lysosomal membrane where they will interact with proteins such as LAMP2 (lysosome-associated membrane protein type 2A). After getting unfolded, proteins will get internalized in the lysosome and subsequently degraded by lysosomal hydrolases (Figure 1). The less investigated microautophagy relies on the direct invagination of the lysosomal membrane to engulf cytosolic cargos. Finally, macroautophagy, also known as autophagy, is the best characterized pathway. ${ }^{2}$ This mechanism is initiated with the formation of a phagophore, a cup-shaped double membrane that engulfs the cytoplasmic material to be degraded. The phagophore is then elongated and sealed 
to generate an autophagosome that will fuse with the lysosome, thereby delivering the cargo for its degradation (Figure 1).

Autophagy is involved in several essential cellular processes. As example, it has a key role under starving conditions by enabling the recycling of cellular proteins, lipids or carbohydrates. Moreover, it also prevents pathogen infection and participates in the elimination of protein aggregates and in the clearance of misfolded and ubiquinated proteins and damaged organelles. Due to this essential role in cellular homeostasis, excessive or deficient levels of autophagy are responsible for several pathologies and are strongly associated with aging processes. $^{3}$ Briefly, down-regulation of autophagy impairs the clearance of aggregated proteins and is correlated with the progress of neurodegenerative diseases such as Parkinson, Alzheimer or the Huntington disease. ${ }^{4}$ Similarly, aging processes are characterized by deficient levels of autophagy and consequently lifespan extension and longevity are clearly linked to the capacity of accurately regulate autophagy. ${ }^{3}$ Dysfunction of this pathway has also been related with cancer. In the early stages of tumorigenesis autophagy seems to function as an alternative apoptotic pathway inducing the death of certain cells. ${ }^{5}$ However, upon chemotherapy or radiotherapy cancer cells may induce protective autophagy as a way to escape from the stress and hypoxia conditions caused by the treatment and ultimately to acquire resistance and capacity for survival. Hence, due to the implication of autophagy in these relevant diseases, the identification of chemical modulators that can regulate autophagy either positively or negatively has became an emerging area of research.5, 6 Autophagy inducers are seen with great interest for the development of novel therapeutic strategies for the treatment of neurodegenerative diseases and as longevity agents, that is compounds able to extent the expected lifespan. ${ }^{6}$ On the contrary, autophagy inhibitors may be employed in diseases characterized with excessive levels of cellular autophagy as is the case of several types of cancers, particularly the ones resistant to treatment. ${ }^{7}$ 8 The combination of chemotherapy and autophagy inhibitors have already showed promising results in the treatment of several types of cancers, thus confirming this hypothesis. ${ }^{7}$

An important point in order to develop new autophagy modulators is to understand in more detail the mechanism that regulates this process. Cellular autophagy is a complex process that involves many signalling pathways and consequently it can be regulated at multiple stages (Figure 1). The first step in autophagy is the formation of the initial phagophore that starts with the nucleation of a specific membrane and the sequestration of the cargo to be degraded. There are many pathways that regulate this initial step. The classic regulating pathway is the mTOR (mammalian target of rapamycin)-signalling pathway although other signalling cascades independent of mTOR have also been described.

The mTOR pathway is a signalling network that connects extracellular and intracellular signals to adapt the cellular metabolism to nutrient fluctuations. Under nutrient rich conditions or in the presence of insulin, this pathway is activated (and autophagy inhibited) to promote anabolic cell growth. Contrarily, the depletion of nutrients or growth factors leads to a decrease in its activity. As a consequence, cells initiate autophagy, that is the breakdown and recycle of 
unnecessary proteins or cellular components, with the aim to keep cellular homeostasis. The key role of mTOR pathway in autophagy regulation has been proven by the induction of lifespan extension upon genetic and chemical inhibition of mTOR-signalling.9, 10 Other key regulators of autophagy do not involve the mTOR network. Hence, modulation of the cellular calcium content or of the inositol 1,4,5-triphosphate $\left(\mathrm{IP}_{3}\right)$ levels can also regulate autophagy in a mTOR-independent manner (Figure 1).

After the initial formation of the phagophore, depending or not on mTOR activity, the phagophore is then elongated and closes to form the autophagosome. The final step is the fusion of the resulting autophagosome with the lysosome, forming an autophagolysosome, and the enzymatic digestion of autophagosome cargo by lysosomal hydrolases.

As a result of the crucial role of the mTOR-signalling pathway in the negative regulation of autophagy, most of the currently known autophagy inducers act by blocking members of this signalling cascade. Moreover, other autophagy inducers that act by lowering $\mathrm{IP}_{3}$ levels or by decreasing cytosolic calcium content have been also described. Some autophagy inhibitors have been also reported. This category includes kinase inhibitors blocking the activity of phosphatidylinositol 3kinases (PI3K), compounds targeting directly or indirectly lysosomal hydrolases, and inhibitors of the lysosomal fusion with the autophagosome.

In this review, an overview will be given on the autophagy modulators described up to now with the main purpose of giving the chemists interested in this research field a broad overview on the existing autophagy modulators and the methods employed for their identification. Most of the methods employed to monitor autophagy rely on the detection of the lipidated autophagy marker LC3-II (MAP1LC3, Microtubule-associated proteins 1A/1B light chain 3, see below) employing antibodies recognizing both the non-lipidated LC3-I as well as LC3-II. Fluorescence microscopy approaches using various labelled proteins (GFP-LC3 or mRFP-LC3-eGFP) or electron microscopy methods have been also widely used. Since the methods employed to assess autophagy will not be described in detail in this revision article, for a complete overview on the existing assays to monitor changes in autophagy levels, the reader is referred to an excellent review covering all the described methods. ${ }^{11}$

The compounds will be initially divided depending on their activity as autophagy inducers or inhibitors. In each category, the described modulators will be classified according to their target and compound classes. Some of the included compounds have been identified after high-throughput screening (HTS) assays employing compound libraries. In some other cases, a rational design based on activity and structural information has been employed. For the most relevant modulators, the synthetic methods employed to obtain these compounds as well as their selectivity profile and the factors involved on their design will be described in more detail. Moreover, since the biological activity and selectivity profile of the chemical modulators will be also reported, we expect that this revision article may also serve as starting point for choosing of control substances in biological assays or drug discovery processes. 

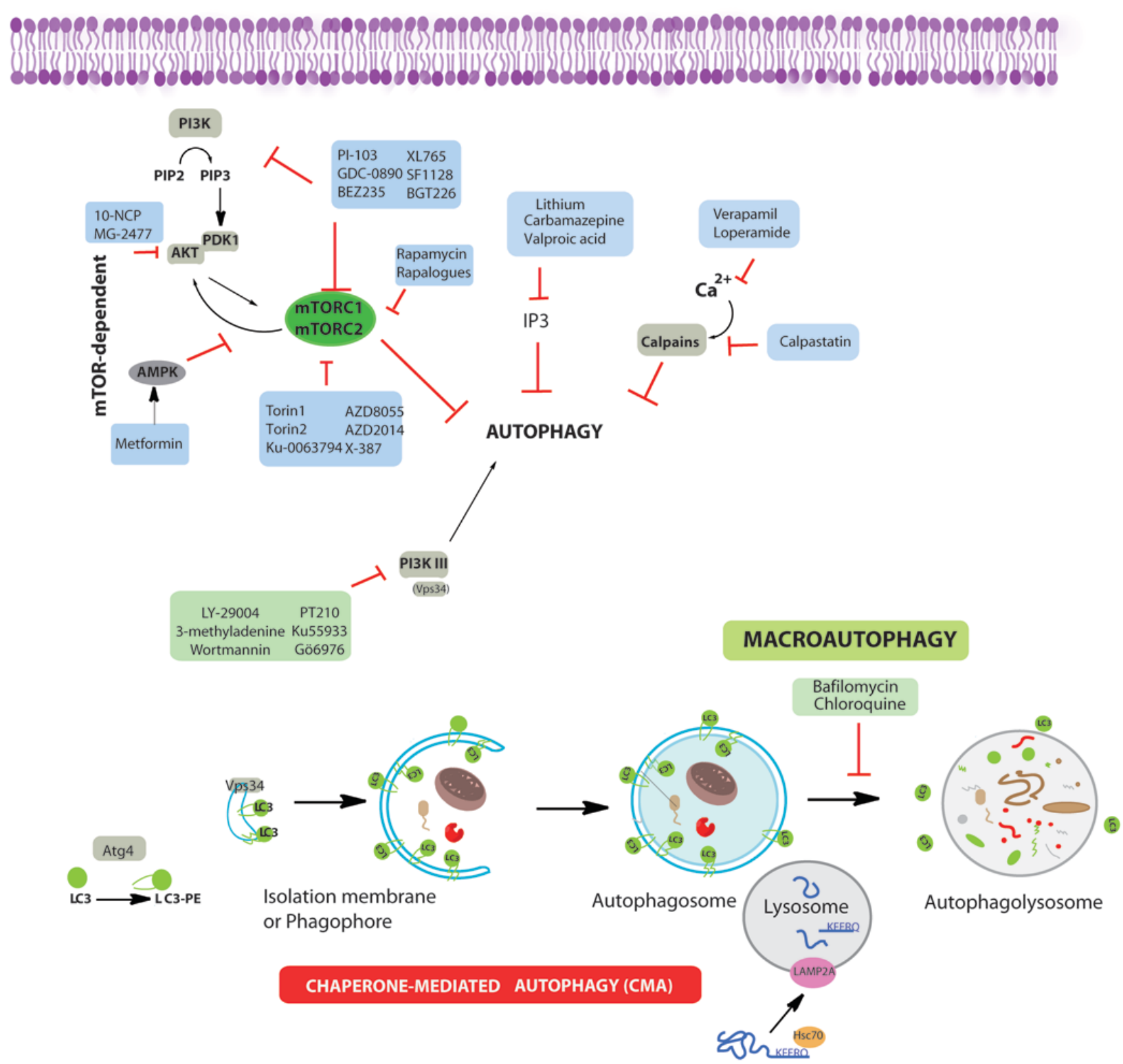

Figure 1. Signalling pathways involved in autophagy (Macroautophagy and Chaperone-mediated autophagy) regulation including the described inhibitors (in green squares) and inducers (in blue squares). 


\section{AUTOPHAGY INDUCERS}

\section{mTOR-dependent pathway}

The best characterized regulator of autophagy is nutrient availability. Consequently, the classical and most important pathway involved in autophagy regulation is the mTOR pathway. ${ }^{12}$ This pathway has a crucial role in the regulation of protein synthesis, cell growth and proliferation. The central molecule of this signalling network is the protein kinase mTOR, after which the complete pathway is named. When nutrients are abundant, mTORC1 phosphorylates ULK-1 and by doing so blocks autophagy initiation, whereas when nutrients are limited, mTORC1 dissociates from the ULK1 complex and initiates the autophagy process. Inhibition of mTOR pathway by directly acting on the mTOR kinase or on downstream kinases such as PI3K, AMPK (AMP-activated protein kinase) or AKT has been widely investigated for the search of autophagy inducers and will be described below. Most of the compounds belonging to this section are protein or lipid kinase inhibitors.

\section{Rapamycin and rapalogues}

Rapamycin was first isolated in 1975 from a soil sample. This macrolide produced by Streptomyces hygroscopius was originally classified as antifungal agent and its name derives from its origin in the Easter Island, known locally as Rapa Nui. ${ }^{13}$ Rapamycin (also known as sirolimus, Pfizer/Wyeth) is used as immunosuppressant in the prevention of transplant rejection. Moreover, rapamycin synthetic derivatives (rapalogues) with reduced immunosuppressive effects and improved pharmacokinetic properties, such as everolimus (RAD001, Novartis), the water soluble prodrug temsirolimus (CCI-779, Wyeth), zotarolimus (ABT-578) and ridaforolimus, formerly known as deforolimus (AP-23573, Merck), have been developed. ${ }^{14}$ Although the rapalogues were mainly designed for cancer treatment they have also shown their potential use as anti-aging agents ${ }^{10}$ (Figure 2).

A key breakthrough in rapamycin research was the identification of its mode of action and target. Rapamycin binds and inhibits mTOR (mammalian target of rapamycin) that was named as a result of this discovery. More specifically, rapamycin binds the peptidyl-prolyl cis-trans isomerase FKBP12 and the resulting complex binds to the FRB domain (FKBP12-rapamycin-binding) of mTOR that results in mTOR allosteric inhibition. ${ }^{15}$ FKB12 can not bind the FRB domain of mTOR in absence of rapamycin, thus rapamycin acts as protein-protein interaction stabilizing agent that mediates the formation of a ternary complex. ${ }^{16}$ The high affinity of rapamycin for FKBP12 $(\mathrm{Kd}=0.2 \mathrm{nM})$ and FRB relies on a number of key hydrogen bonds involving the pipecolic acid region, the tricarbonyl region from $\mathrm{C}$ 8 to $\mathrm{C}-10$, and the lactone functionalities. The triene region (C16-to C-23) of rapamycin also present important hydrophobic contacts with aromatic residues in the FRB domain (Figure 2). ${ }^{17}$

mTOR is present in two different protein complexes: mTORC1 that regulates protein synthesis, cell growth and proliferation after sensing of nutrients, growth factors and energy, and mTORC2 that promotes cellular survival by activating AKT, upstream of mTOR (Figure 1). Activated AKT can in turn activate mTORC1 in 
which is known as a feedback loop. Since Rapamycin affects only mTORC1 activity, these derivatives are not able to block the feedback loop involving AKT and consequently they present insufficient clinical efficiency.
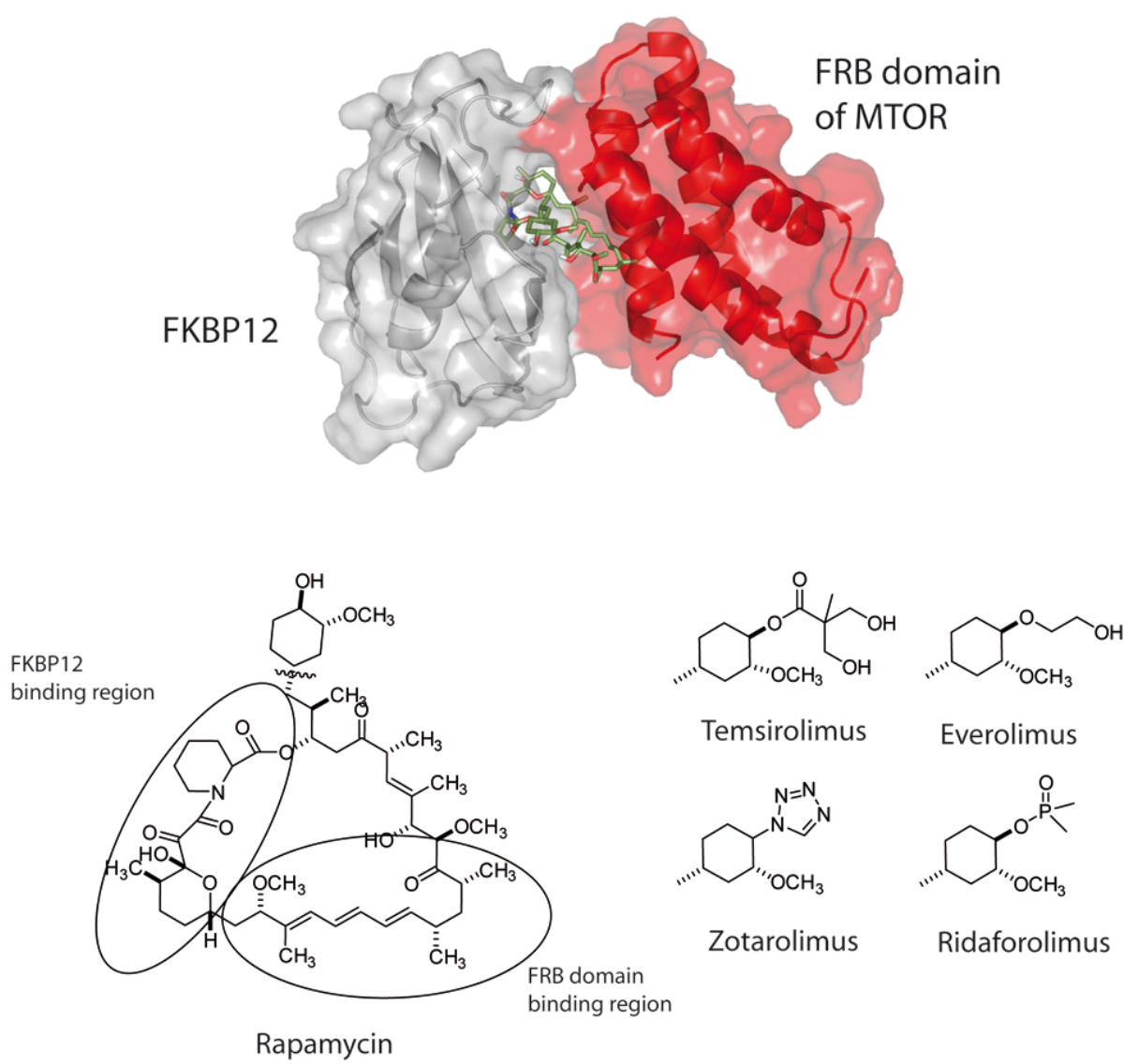

Figure 2. X-ray co-crystal structure of the ternary complex formed by FKBP12, the FRB domain of mTOR and rapamycin. Chemical structure of rapamycin and the rapalogues highlighting the FKBP12 and FRB-binding regions.

Inhibition of mTOR causes an autophagy response that is comparable to nutrient starvation. Thus, Rapamycin (10 to $500 \mathrm{nM}$ ) and amino acid deprivation are still widely used as positive control method in basic research to induce autophagy. However, Rapamycin effects as autophagy inducer may be slow, transient and cellspecific (a weaker effect has been observed on neurons compared to non-neuronal cells). ${ }^{18}$ As a result, specific mTOR inhibitors that target the ATP binding site of the serine/threonine (Ser/Thr) kinase mTOR and the lipid kinase PI3K have emerged in the last years and have shown to be more potent inducers of autophagy than Rapamycin. Some of the most representative examples of this inhibitor classes, PI103, BEZ235, PP242, Torin, Ku0063794, as well as their synthesis, will be described in detail below.

Kinases are the major regulators and transducers of signalling in eukaryotic cells. These enzymes transfer phosphate from adenosine triphosphate (ATP) to their substrates, which can be proteins to be phosphorylated at serine, threonine, tyrosine or histidine residues or lipids, such as phosphatidylinositol (PI), which can be phosphorylated at one or more hydroxyls at the inositol ring. Protein kinase is one of the largest enzyme families and comprises more than 500 members that 
share high similarities at the catalytic kinase domain and the ATP binding site. Consequently, the search for selective kinase inhibitors targeting the ATP binding site of a particular kinase without affecting many other kinases has been a major challenge in research. In the last decade, several advances in structural biology and novel medicinal chemistry approaches have enabled the synthesis of potent and selective kinase inhibitors. Most of the identified kinase inhibitors are ATPcompetitive. These compounds usually contain a heterocycle that mimics the hydrogen bonds formed by the adenine ring of ATP with residues located at the ATP-binding site and different substitution patterns directed to fill the hydrophobic pockets present in the binding site. ${ }^{19}$

\section{Dual PI3K class I and mTOR inhibitors}

The alternative AKT activation seen with rapamycin and the rapalogues made necessary alternative strategies blocking also this feedback loop. This led to the development of multitargeting compounds that simultaneously inhibit two or more proteins in the PI3K/AKT/mTOR pathway.

Although mTOR is a Ser/Thr kinase, it is closely related to the family of the lipid kinase PI3K. The similarity in the catalytic domains of mTOR and PI3K have facilitated the search for inhibitors able to simultaneously block the ATP binding sites of both mTOR and PI3K kinases. In mammalian cells, PI3K have been divided in three classes (class I, II and III) on the basis of its lipid substrate specificity. ${ }^{20}$ The class I leads to AKT activation by the phosphoinositide-dependent kinase-1 (PDK1) and mTORC2, and the activated AKT acts on tuberous sclerosis complex (TSC1, TSC2) and Rheb, leading to mTORC1 activation that causes autophagy inhibition. Hence, small-molecule inhibitors blocking both PI3K and mTOR would have the advantage of shutting down completely the PI3K/AKT/mTOR pathway and thus avoiding the feedback activation, seen by rapamycin and the rapalogues. As a result, the search for dual PI3K/mTOR inhibitors blocking the ATP binding cleft of both enzymes has emerged as an interesting area of research.

The PI3K/AKT pathway has a crucial role in controlling cellular growth and proliferation and is often altered in cancer. Therefore, great efforts have been done to find potent PI3K inhibitors as novel agents for cancer treatment. The development of dual PI3K/mTOR inhibitors has strongly benefited from these previous studies yielding interesting compound classes that will be summarized below.

PI-103 and derivatives

Class I PI3K can be further divided in IA (which can consist on three different catalytic subunits (p110 $\alpha, \beta$ or $\delta$ ) and IB (p110 $\gamma$ ). One of the first described PI3K/mTOR dual inhibitors, PI-103, was identified after a HTS assay aimed to find p110 $\alpha$ inhibitors.

PI-103 emerged initially from a collaboration between the Yamanouchi pharmaceutical company, later Astellas, and the group of Paul Workman at the Institute of Cancer Research (UK). The screening of a compound library based on 4-morpholino-2-phenylquinazoline and related analogues yielded the scaffold $\mathbf{1}$ as initial hit. Structural modification of $\mathbf{1}$ resulted in a furan analogue with an aryl group on the pyrimidine ring. A focused library based on this improved scaffold 
enabled the identification of PI-103, containing a morpholino pyridofuropirimidine core and bearing a hydroxyl group at the 3 position of the benzene ring. ${ }^{21}{ }^{22}$ Biological evaluation of PI-103 confirmed low nanomolar inhibition of class I PI3K, mTORC1 and mTORC2 in in vitro studies as well as cellular activity (Figure 3, Table 1). ${ }^{22,} 23$ The activity of PI-103 as autophagy inducer in several cancer cells have also been explored. ${ }^{24}$

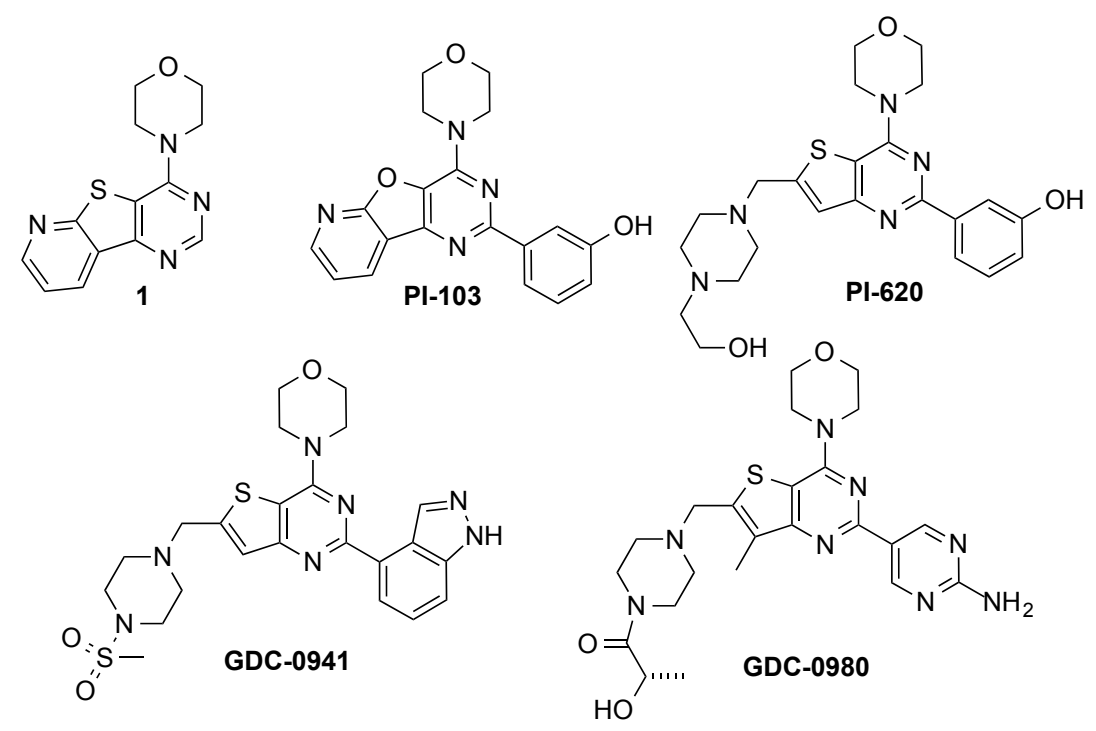

Figure 3. Structure of PI-103 and derivatives with improved activity and pharmacokinetic properties.

The synthesis of PI-103 can be seen in Scheme 1. PI-103 was synthesized starting from 2-chloronicotinonitrile upon treatment with ethyl-2-hydroxyacetate in the presence of DBU yielding the bicyclic ester 3 . Upon acylation of $\mathbf{3}$ with the corresponding aryl chloride, compound $\mathbf{4}$ was obtained, which was transformed to diamide 5 by hydrolysis, conversion to the corresponding acyl chloride with thionyl chloride, and subsequent treatment with $\mathrm{NH}_{4} \mathrm{OH}$. After cyclization under basic conditions, demethylation with $\mathrm{HBr}$ followed by chlorination with phosphorus oxychloride and nucleophilic substitution with morpholine, the final pyridylfuranopyrimidine PI-103 was obtained. 

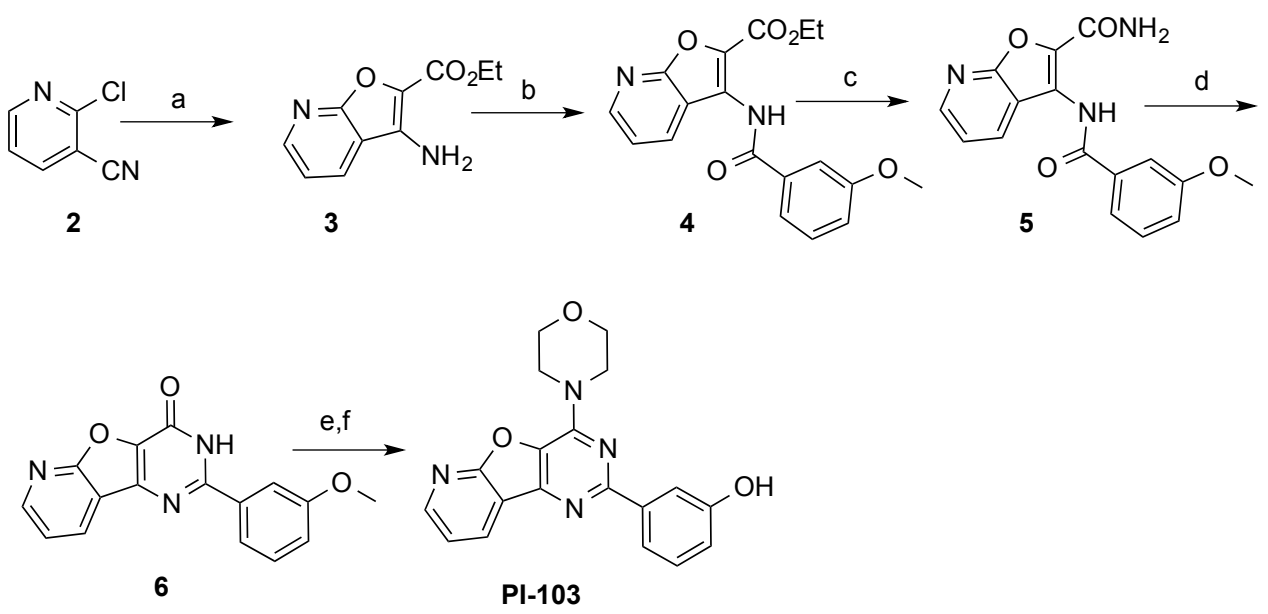

Scheme 1. Reagents and conditions a) $\mathrm{HOCH}_{2} \mathrm{CO}_{2} \mathrm{Et}, \mathrm{DBU}, \mathrm{EtOH}$, reflux; b) 3$\mathrm{MeOArCOCl}, \mathrm{Et}_{3} \mathrm{~N}$ or pyridine, THF or $\mathrm{CHCl}_{3}$; c) i) $1 \mathrm{~N} \mathrm{NaOH}, \mathrm{EtOH}$; ii) SOCl2, reflux; iii) $\mathrm{NH}_{4} \mathrm{OH}$, THF; d) $2 \mathrm{~N} \mathrm{NaOH}, \mathrm{MeOH}$ or 2-PrOH, reflux; e) i) $\mathrm{HBr}, \mathrm{AcOH}$, reflux; ii) $\mathrm{Ac}_{2} \mathrm{O}, \mathrm{AcONa}$, reflux; f) i) $\mathrm{POCl} 3$, d; ii) morpholine, toluene or neat, reflux;

The basis of the specificity of PI-103 for mTOR and Class I PI3K has been recently revealed upon co-crystallization of mTOR with PI-103. The crystal structure indicates that the morpholine ring binds to the adenine pocket of mTOR and makes two hydrogen bonds to the hinge, whereas the phenol group binds to the inner pocket and makes two additional hydrogen bonds with Tyr2225 and Asp2195. These relevant residues are similarly located in PI3K which would explain the high specificity of this inhibitor for these two kinases. ${ }^{25}$

Although PI-103 was one of the first examples of dual PI3K/mTOR inhibitor and it still remains as a good tool for basic research, its poor pharmacokinetic properties due to the planar tricyclic structure and its rapid in vivo metabolism through glucoronidation of the phenolic hydroxyl group precluded clinical optimization. ${ }^{23}$ Hence, optimized compounds with improved solubility and pharmacokinetic properties were required. A medicinal chemistry approach led to the identification of compounds meeting these requirements such as the byciclic thienopyrimidine derivative PI-620 and the clinical development candidate GDC-0980 (Figure 3). ${ }^{26}$, 27 These compounds contain a piperazine-based functionality at the ring that increase their solubility. Moreover, replacement of the phenol by an indazole reduced glucoronidation while maintaining interactions with the ATP binding site of PI3K leading to GDC-0941. ${ }^{28}$ However, whereas PI-620 and GDC-0941 retained a good selectivity towards class I PI3K, their mTOR inhibitory activity was strongly reduced (Table 1). This was solved by the replacement of the indazole in GDC0941 by a 2-aminopyrimidine that resulted in a 20 -fold increase in mTOR inhibition. Further modifications to improve pharmacokinetic properties included the introduction of a methyl group to increase metabolic stability and the installation of hydroxy acids at the piperazine ring. These changes led to the more soluble GDC-0980 that retained activity and presented increased thermodynamic solubility at neutral $\mathrm{pH}$, low to moderate clearance, good oral bioavailability and efficacy in animal cancer models. ${ }^{29}$ These compound were licensed to Genentech/Roche and are being studied in several clinical trials for the treatment of cancer. Although the effect of these dual PI3K/mTOR inhibitors has been mainly 
explored in regard to cancer progression, its activity as autophagy inducers in cell studies has been initially explored as well. ${ }^{30}$

The synthetic route to GDC-0980 is shown in Scheme 2 and starts with 7 that is in turn prepared in three steps from methyl-3-amino-2-thiophenecarboxylate. ${ }^{31} \alpha$ Lithiation of $\mathbf{7}$ and subsequent formylation with DMF yielded aldehyde $\mathbf{8}$ that after reductive amination with Boc-piperazine followed by Suzuki coupling with 2aminopyrimidine-4-boronic acid afforded 10. The formation of the final amide with hydroxypropionic was performed in the last step after Boc deprotection due to the instability of this group to the high temperature Suzuki reaction affording GDC-0980.29
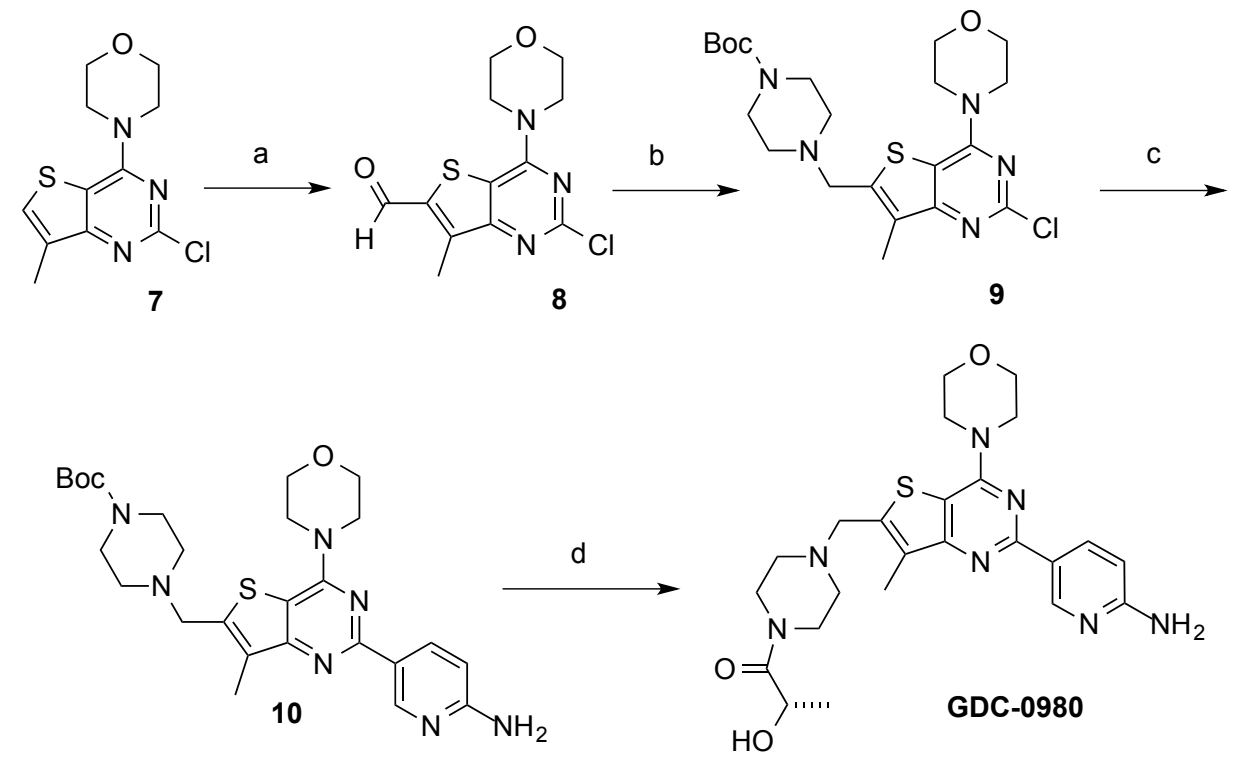

Scheme 2. Reagents and conditions a) n-BuLi, THF, $-78{ }^{\circ} \mathrm{C}, \mathrm{DMF}-40^{\circ} \mathrm{C}$; b) Bocpiperazine, 1,2-DCE, $\mathrm{HC}\left(\mathrm{OCH}_{3}\right)_{3}, \mathrm{Na}(\mathrm{OAc})_{3} \mathrm{BH}, 96 \%$; c) 2-aminopyrimidine-5boronic acid pinacol ester, $\mathrm{Pd}\left(\mathrm{PPh}_{3}\right)_{2} \mathrm{Cl}_{2}, 1 \mathrm{M} \mathrm{Na}_{2} \mathrm{CO}_{3}, \mathrm{CH}_{3} \mathrm{CN}$, microwave, $140{ }^{\circ} \mathrm{C}$, $15 \mathrm{~min}, 82 \%$; d) $4 \mathrm{~N} \mathrm{HCl}$ in dioxane, $\mathrm{DCM}, 25^{\circ} \mathrm{C}, 3 \mathrm{~h}, 100 \%$; (S)-2-hydroxypropionic acid, $\mathrm{N}, \mathrm{N}$-diisopropylethylamine (DIPEA), 1-[Bis(dimethylamino)methylene]-1H1,2,3-triazolo[4,5-b]pyridinium 3-oxid hexafluorophosphate (HATU), DMF, $25^{\circ} \mathrm{C}$, $30 \mathrm{~min}, 56 \%$.

\section{NVP-BEZ235}

A medicinal chemistry approach aimed to develop 3-phosphoinositide-dependent kinase-1 (PDK1) inhibitors, the Ser/Thr kinase involved together with PI3K, in the activation of AKT, yielded the imidazo[4,5-c] quinolone derivative 11 (Scheme 3) that also inhibit class I PI3K $\mathrm{K}^{32}$ and induce autophagy in cells. ${ }^{33}$ Further development of this compound led to analogues lacking PDK1 activity (12) and finally to the dual PI3K/mTOR inhibitor BEZ235 (Novartis). ${ }^{34}$ Briefly, the replacement of the methylcyano by a dimethylcyano group together with the introduction of a methyl group on the imidazole ring yielded compound $\mathbf{1 2}$ (Scheme 3) with reduced PDK1 inhibitory activity while keeping PI3K activity. Additional change of the imidazo ring to $\mathrm{N}$-methylimidazolinone resulted in a complete loss in PDK1 inhibitory activity while keeping PI3K activity and afforded 
BEZ235 with an increased selectivity for class I PI3K isoforms, and also activity for mTOR as well as in vivo antitumor activity (Table 1). ${ }^{34}$ Additional studies in several cancer cells have also confirmed cell death or potent growth inhibition via massive autophagy induction by BEZ235 and the derivative BGT226 even at low nanomolar concentrations. ${ }^{35}$ The specificity of BEZ235 for PI3K in front of PDK1 was revealed by docking studies that suggested an electrostatic mismatch between the carbonyl group at position 2 and a backbone carbonyl of Leu88 in PDK1 that has no equivalent in PI3K. ${ }^{32}$
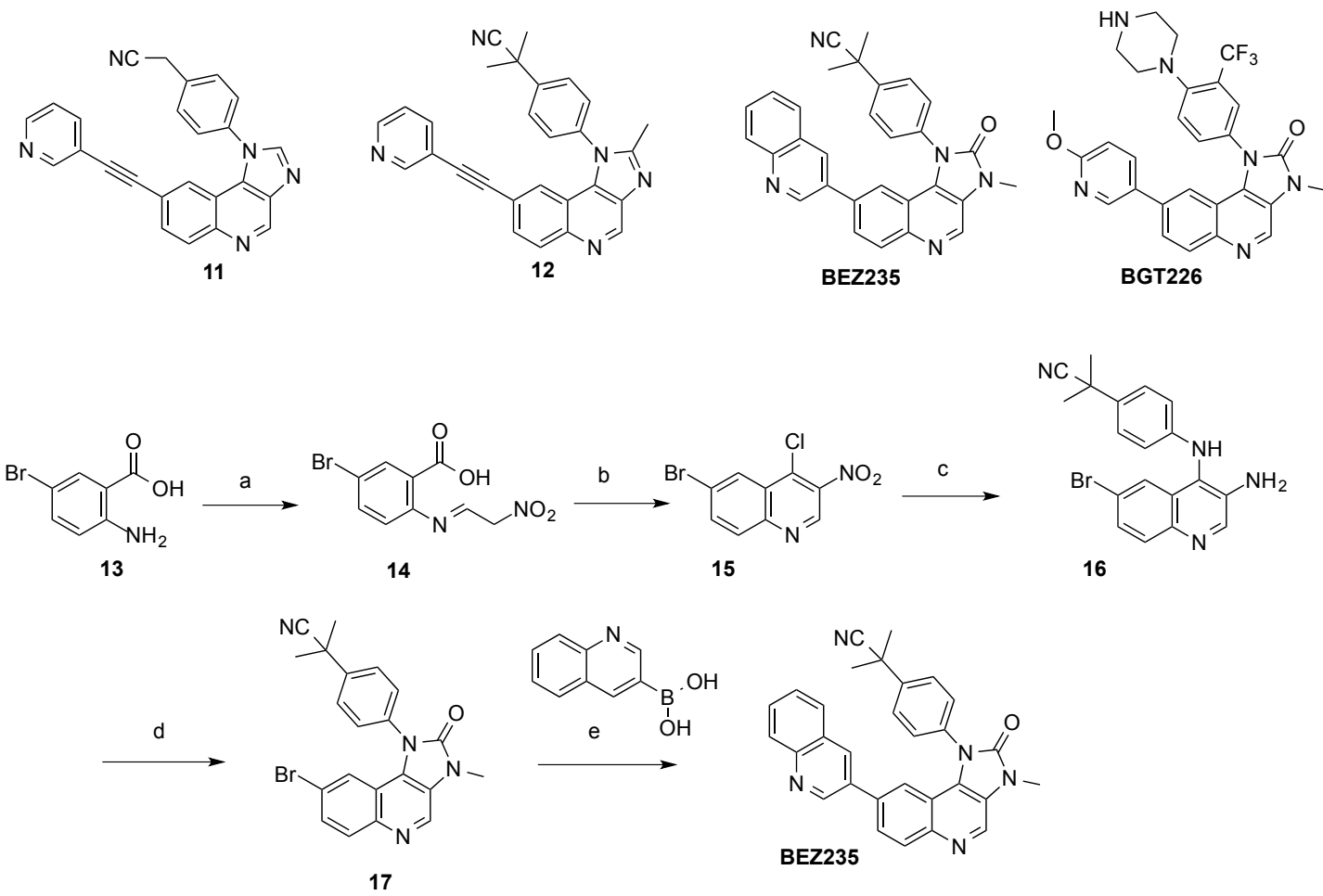

Scheme 3. Reagents and conditions. a) nitromethane $\mathrm{NaOH}, 1 \mathrm{~h} 0^{\circ} \mathrm{C}, 1 \mathrm{~h} \mathrm{rt}$, then $\mathrm{HCl}$ added, mixture is added to the reaction, $18 \mathrm{~h} \mathrm{rt}$; b) i) $\mathrm{CH}_{3} \mathrm{COOK}, \mathrm{Ac}_{2} \mathrm{O}, 1.5 \mathrm{~h}$ $120^{\circ} \mathrm{C}$; ii) $\mathrm{POCl}_{3}, 45 \mathrm{~min} 120^{\circ} \mathrm{C}, \mathrm{c}$ ) i) (2-(4-aminophenyl)-2-methylpropionitrile, $\mathrm{AcOH}, 2 \mathrm{~h}$; ii) $\mathrm{H}_{2}$, raney $\mathrm{Ni}$, THF:MeOH (1:1), $12 \mathrm{~h}$, rt; d) i) $\mathrm{Cl}_{3} \mathrm{COCOCl}, \mathrm{NEt}_{3}, \mathrm{CH}_{2} \mathrm{Cl}_{2}$; ii) $\mathrm{CH}_{3} \mathrm{I}, \mathrm{Bu}_{4} \mathrm{NBr}, \mathrm{CH}_{2} \mathrm{Cl}_{2}: \mathrm{NaOH}$ aq; e) 3-quinoline boronic acid, $\mathrm{Pd}\left(\mathrm{PPh}_{3}\right)_{2} \mathrm{Cl}_{2}, \mathrm{DMF}$, $95^{\circ} \mathrm{C} 2 \mathrm{~h}$.

The synthesis of BEZ235 is depicted in Scheme 3. Condensation of bromosubstituted anthranilic acid hydrochloride with methazonic acid, prepared in situ from nitromethane and sodium hydroxide, yielded the 2-(2nitroethylideneamino)-5-bromobenzoic acid 14. Dehydration by acetic anhydride in the presence of potassium acetate followed by treatment with phosphorus oxychloride of the resulting 3-nitro-4-hydroxyquinoline afforded 15.36 This 3nitro-4-chloroquinoline underwent nucleophilic aromatic substitution with (2-(4aminophenyl)-2-methylpropionitrile and the nitro group was reduced by catalytic hydrogenation using Raney nickel as a catalyst giving the 3,4-diaminoquinoline 16. Compound 17 was prepared after ring closure of 16 with trichloromethyl chloroformate and subsequent alkylation with methyl iodide. Finally, the Suzuki coupling of $\mathbf{1 7}$ with 3-quinoline boronic acid afforded BEZ235. ${ }^{37}$ 
Another dual mTOR/PI3K inhibitors is XL765 developed by Exelixis and later outlicensed to Sanofi (SAR245409). XL765 inhibits mTOR and the PI3K subunits $\mathrm{p} 110 \alpha, \beta, \gamma$ and $\delta$ causing cell growth inhibition and accumulation of autophagosomes in MIAPaCa-2-cells. Moreover, the treatment of a panel of pancreatic cancer cells with XL765 induced enhanced apoptotic cell death and greater autophagy induction than the separate inhibition of PI3K and mTOR pathway. ${ }^{38}$ Another PI3K inhibitor that also blocks mTOR activity, albeit weakly, is caffeine that in high doses enhances autophagic flux acting on the PI3K/mTOR/p70S6 signalling pathway. ${ }^{39}$ This autophagy induction would be in agreement with studies showing that caffeine can increase life span in yeast by targeting mTORC1. ${ }^{40}$ Other potent dual mTOR/PI3K inhibitors have been recently described (18) although their activity as autophagy inducers has not been explored yet (Figure 4). ${ }^{41}$<smiles>COc1cc(Nc2nc3ccccc3nc2NS(=O)(=O)c2ccc(NC(=O)c3ccc(C)c(OC)c3)cc2)cc(OC)c1</smiles>

SAR245409 (XL765)<smiles>Cn1c(=O)c2c(ncn2C)n(C)c1=O</smiles>

Caffeine<smiles>O=C(Cc1ccc(CO)cc1)Nc1ccc(-c2nc(N3CCOCC3)c3ncccc3n2)cc1</smiles>

18

Figure 4. XL765, Caffeine and the pyridopyrimidine 18 are autophagy inducers with known inhibiting activity of the kinases mTOR and PI3K.

Table 1. Activities of the reported dual mTOR/PI3K inhibitors. Values obtained using an in vitro kinase assays using expressed PI3K and a) precipitated mTOR or b) expressed mTOR.

\begin{tabular}{|c|c|c|c|c|c|}
\hline & & \multicolumn{4}{|c|}{$\mathrm{IC}_{50}(\mathrm{nM})$} \\
\hline & \multirow[t]{2}{*}{ PDK1 } & \multicolumn{3}{|c|}{ PI3K } & \multirow{2}{*}{ mTOR } \\
\hline & & $\mathrm{p} 110 \alpha$ & $\mathrm{p} 110 \beta$ & $\mathrm{p} 110 \gamma$ & \\
\hline PI-103a, 22 & - & 2 & 3 & 15 & 20 \\
\hline PI-620b, 26 & - & 7 & 63 & 672 & 231 \\
\hline GDC-0941 b, 26 & - & 3 & 33 & 75 & 580 \\
\hline GDC-0980 b, 29 & - & 4 & - & - & 21 \\
\hline $11^{b, 32}$ & 34 & 64 & 432 & 67 & \\
\hline $12^{b, 32}$ & 245 & 56 & 446 & 47 & \\
\hline BEZ235 b,32 & $>25000$ & 4 & 75 & 5 & 6 \\
\hline XL765 b,38 & - & & - & - & \\
\hline $18^{\mathrm{b}, 41}$ & & 58 & & & 5 \\
\hline
\end{tabular}

Most of these dual inhibitors have been mainly investigated as anti cancer agents more than as autophagy inducers. As a result doses required for autophagy induction are not well known and may vary depending on the cell type. However, some preliminary results have already explored their effect as autophagy inducers and more particularly, the administration of dual PI3K/mTOR inhibitors together 
with unselective autophagy inhibitors have shown promising results in causing apoptosis in several cancer cell types such as glioma, leukaemia. ${ }^{42}$

\section{Pan mTOR inhibitors}

As an alternative strategy to block the feed-back activation of AKT, a second and more potent generation of mTOR inhibitors targeting the ATP binding site of the mTOR kinase and affecting both protein complexes, MTORC1 and MTORC2 has been developed. ${ }^{14}$ Again, as for the above mentioned dual PI3K/mTOR inhibitors, pan-mTOR inhibitors have shown promising results in radio and chemoresistant cancer cells. Autophagy is a cell survival strategy in cancer cells and although mTOR inhibition activates autophagy, it seems that may also enhance their sensitivity to treatment by triggering premature senescence. The mechanism controlling this process is yet under investigation but the use of autophagy inducers blocking mTOR activity may be considered an alternative strategy for cancer treatment. ${ }^{43}$

\section{PP242}

The first pan-mTOR inhibitors PP242 and the analogue PP30, were initially discovered by the group of Kevan M. Shokat in a HTS assay directed to find PI3K and Ser/Thr kinase inhibitors. ${ }^{44,} 45$ These compounds have an adenine-mimetic pyrazolopyrimidine scaffold and selectively inhibit mTORC1 and mTORC2 with low nanomolar IC $_{50}$ without affecting other kinases (Table 2). Moreover these compounds together with the other pan-mTOR inhibitors are more efficient than rapamycin in blocking cell proliferation and are stronger autophagy agonist in several cell lines. ${ }^{45}$

The synthetic route to PP242 can be seen in Scheme 4 and starts upon refluxing 3amino-4-pyrazolecarbonitrile with an excess of formamide yielding the 4-amino substitute pyrazolo[3,4-d]pyrimidine 19. Iodation using $\mathrm{N}$-iodosuccinimide followed by alkylation with isopropylbromide yielded intermediate $\mathbf{2 0}$ that after a Suzuki reaction with 5-benzyloxy-1-Boc-indole-2-boronic acid followed by debenzylation afforded the final compound PP242 (Scheme 4). ${ }^{44}$

The X-ray co-crystal structure of PP242 with mTOR has been recently reported indicating that the selectivity of PP242 for mTOR vs PI3K probably relies on a conformational change involving Leucine 2354 that enables the hydroxyindole of PP242 to fill a deeper hydrophobic pocket. A similar change is not possible in PI3K due to the replacement of the, leucine by a phenylalanine. ${ }^{25}$ 
<smiles>CC(C)n1nc(I)c2c(N)ncnc21</smiles><smiles></smiles><smiles>CC(C)CCCCC(C)n1nc(-c2cccc(C(=O)NC3=NCCS3)c2)c2c(N)ncnc21</smiles>

Scheme 4. Synthesis of PP242 and chemical structure of the analogue PP30. Reagents and conditions: a) formamide, $180^{\circ} \mathrm{C}, \mathrm{o} / \mathrm{n}$; b) i) NIS, DMF $80^{\circ} \mathrm{C}$; ii) $\mathrm{K}_{2} \mathrm{CO}_{3}$, $\mathrm{DMF}, 80^{\circ} \mathrm{C}$, isopropylbromide; c) 5-benzyloxy-1-boc-indole-2-boronic acid, EtOHDME, $\mathrm{Pd}\left(\mathrm{PPh}_{3}\right)_{4}$ saturated $\mathrm{Na}_{2} \mathrm{CO}_{3}, 80^{\circ} \mathrm{C}$; d) formic acid, $\mathrm{HCl}$.

\section{Torin}

Another potent mTOR inhibitor that has been widely used as autophagy inducer is Torin, developed by the group of Nathaniel S. Gray after the screening of a compound library that provided quinolone-based hits with moderate activity for mTOR (5 $\mu \mathrm{M})$ and selectivity against PI3K (Scheme 5). A medicinal chemistry approach based on an iterative process of chemical modification and biological evaluation was then applied yielding more potent and selective compounds. Briefly, varying the side chains at 4- and 6-positions of the quinoline did not result in active cellular compounds. However when these changes were combined with the introduction of a six-membered lactam resulted in Torin, a tricyclic benzonaphthridinone scaffold which inhibited mTORC1 and MTORC2 at pM concentrations in vitro and showing a 1000 fold improved mTOR celluar potency. ${ }^{46}$ Moreover, Torin, presented a good selectivity profile with a 1000 -fold selectivity over PI3K and a 100 -fold selectivity to 450 other protein kinases when screened at $10 \mu \mathrm{M}$ concentration. ${ }^{47}$ Torin together with PP242 (both tested at 1 $\mu \mathrm{M}$ concentration) have shown increased potency compared to rapamycin in inducing autophagy, and the same studies have also indicated that Torin may have an additional effect on the maturation and degradation of autophagy by activating the lysosomal function. ${ }^{48}$

Torin synthesis starts from the dichloroquinoline scaffold 22, which undergoes nucleophilic aromatic substitution with the corresponding aniline to yield compound 23. Reduction of ethylester $\mathbf{2 4}$ followed by alcohol oxidation and subsequent Horner-Wadsworth-Emmons afforded 25. The quinoline side chain is finally then introduced via palladium-mediated coupling with the corresponding boronic acid. 
<smiles>FC(F)(F)c1cccc(Nc2ccnc3ccc(-c4cccnc4)cc23)c1</smiles><smiles></smiles><smiles>CCOC(=O)c1cnc2ccc(Cl)cc2c1Cl</smiles><smiles>CCC(=O)N1CCN(c2ccc(-n3c(=O)cc(C)c4cnc5ccc(Cl)cc5c43)c(C(F)(F)F)c2)CC1</smiles>

Scheme 5. Synthesis of Torin. Reagents and conditions: a) 4-[4propionylpiperazinyl)-3-trifluoromethylaniline, 1,4-dioxane, $100{ }^{\circ} \mathrm{C}$, $4 \mathrm{~h}$; b) $\mathrm{LiAlH}_{4}$, THF, $0^{\circ} \mathrm{C}$ to $\mathrm{rt}$, 4h; c) i) $\mathrm{MnO}_{2}, \mathrm{CH}_{2} \mathrm{Cl}_{2}$, rt, 6h; ii) triethylphosphonoacetate, $\mathrm{K}_{2} \mathrm{CO}_{3}$, EtOH, $100^{\circ} \mathrm{C}, 12 \mathrm{~h}$; d) $\mathrm{PdCl}_{2}\left(\mathrm{PPh}_{3}\right)_{2}, t$-Bu-Xphos, $\mathrm{Na}_{2} \mathrm{CO}_{3}, 1,4$-dioxane, $100^{\circ} \mathrm{C}, 12 \mathrm{~h}$.

More recently Torin2, an analogue with improved pharmacokinetic properties, was described with the aim to overcome the limitations of Torin 1 in terms of lowyielding synthetic route (overall yield 7\%), poor water solubility, short half-life and low oral bioavailability. ${ }^{49}$ Torin2 was obtained starting from 4-chloro-6bromoquinoline following a similar approach and can be seen in Scheme 6 . Nucleophilic aromatic substitution with the appropiate aniline followed by ester reduction with $\mathrm{NaBH}_{4}$, oxidation of the benzylic alcohol and Horner-WadsworthEmmons olefination furnished the tricyclic core scaffold 28. Palladium-mediated coupling reactions to include substitution afforded the target compound Torin2 with a $15 \%$ overall yield. Biochemical and cellular characterization of Torin2

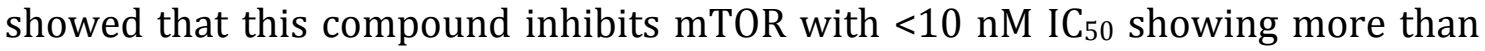
800 -fold selectivity against PI3K. Torin2 also inhibits proliferation of cancer cell, progression of the cell cycle, and induces apoptosis and autophagy. ${ }^{50}$<smiles>CCOc1cnc2ccc(Br)cc2c1Cl</smiles> 
Scheme 6. Synthesis of Torin2. Reagents and conditions: a) 3(trifluoromethyl)aniline, 1,4-dioxane, $90{ }^{\circ} \mathrm{C}, 4-12 \mathrm{~h}$; b) $\mathrm{NaBH}_{4}, \mathrm{EtOH}, \mathrm{rt}, 4 \mathrm{~h}$; c) i) $\mathrm{MnO}_{2}, \mathrm{CH}_{2} \mathrm{Cl}_{2}, \mathrm{rt}, 6 \mathrm{~h}$; ii) triethylphosphonoacetate, $\mathrm{K}_{2} \mathrm{CO}_{3}, \mathrm{EtOH}, 100^{\circ} \mathrm{C}, 12 \mathrm{~h}$; d) $\mathrm{PdCl}_{2}\left(\mathrm{PPh}_{3}\right)_{2}, \mathrm{Na}_{2} \mathrm{CO}_{3}, 1,4$-dioxane, $100^{\circ} \mathrm{C}, 12 \mathrm{~h}$.

The co-crystal structure of Torin 2 with mTOR revealed the mode of binding, confirmed some of the predicted hydrogen bonds and showed extensive stacking of the tricyclic benzonaphthyridinone ring with the indole group of Tryptophan (Trp) 2239. Apart from contributing to the low nM potency of Torin2 this interaction may also have a role in the specificity over PI3K, because Trp 2239 is not present in canonical protein kinases or in PI3K. ${ }^{25}$

$\underline{\mathrm{Ku}-0063794}$

Another ATP-competitive inhibitor of mTORC1 and mTORC2 is Ku-0063794, developed by Astra Zeneca after a HTS assay that yielded the racemate $\mathbf{2 9}$ as initial hit. The replacement of the piperidine by a substituted morpholine reduced the overall lipophilicity and increased the activity. Further optimization was suggested by docking studies using an homology model of mTOR that indicated that the substitution of the pyridopyrimidine at the $\mathrm{C} 7$ position would provide compounds able to access additional pockets in the ATP binding site. Indeed, the incorporation of electron-donating substituents in the para position combined with hydrogen bond donors in the meta position resulted in Ku-0063794 with a low nM IC 50 for mTORC1 and mTORC2 and good selectivity over other 76 kinases and 7 lipid kinases. ${ }^{51}$ With the aim of increasing the aqueous solubility and decreasing sidetarget activity, two additional derivatives were prepared, AZD8055 and AZD2014 which display autophagy induction in cells ${ }^{52}$ and are currently in phase I clinical studies (Figure 5). ${ }^{53}$ The effect of AZD8055 in neurological disorders has also been investigated. Hence, AZD8055 has shown to be a potent autophagy inducer with a $\mathrm{EC}_{50}$ of $180 \mathrm{nM}$ and to cause an increased degradation of mutant huntingtin aggregates in a neuronal cell model of this neurodegenerative disease. Other mTOR inhibitors such as BEZ235 or BKM124 were also active in this assay while the rapamycin analogue everolimus fail to show any effect. ${ }^{54}$ 

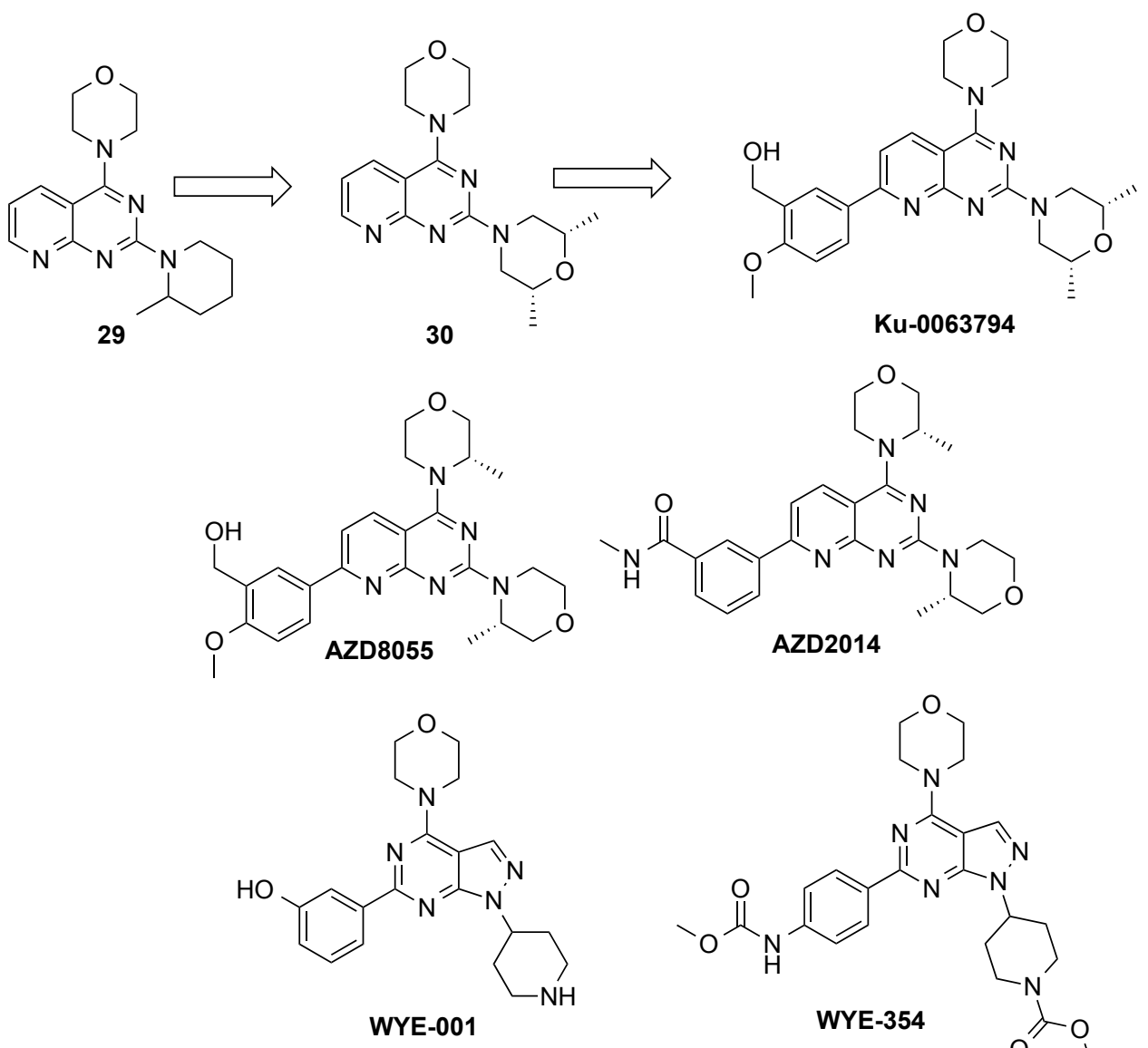<smiles>CNC(=O)c1cccc(-c2ccc3c(N4CCOC[C@@H]4C)nc(N4CCOC[C@H]4C)nc3n2)c1</smiles><smiles>COC(=O)Nc1ccc(-c2nc(N3CCOCC3)c3cnn(C4CCN(C(=O)OC)CC4)c3n2)cc1</smiles>

Figure 5. Structure of the ATP-competitive inhibitor of mTOR Ku-0063794, WYE001 and WYE-354 and the clinical derivatives AZD8055 and AZD2014.

The HTS of a chemical library identified the initial hit WYE-001, that was modified to diminish its potential metabolic liability. The replacement of the phenol by a methyl carbamate and in the introduction of substituents at the piperidine ring led to WYE-354, with low nanomolar activity for mTOR, more tan 100 fold selectivity over class I PI3K $\mathrm{K}^{55}$ and activity as autophagy inducer in cells. ${ }^{56}$ WYE-354 is also an ATP-competitive mTOR inhibitor with a pyrazolopyrimidine scaffold. This inhibitor was developed by Wyeth Discovery Medicinal Chemistry (Figure 5). Another example of this inhibitor class is X-387, a pyrazolopyrimidine compound developed by Xcovery (Figure 6). X-387 inhibits proliferation in a broad range of human tumour cells with $\mathrm{IC}_{50}$ ranging from 0.2 to $1.6 \mu \mathrm{M}$. X-387 also had an effect on autophagy induction as evidenced by the detection of increased levels of LC3-II in a dose-dependent manner. However in this case, autophagy seems to have a protective effect and attenuated the antiproliferative activity of this compound. This effect could be reverted with the concomitant treatment with the autophagy inhibitor 3-methyladenine. ${ }^{57}$ 


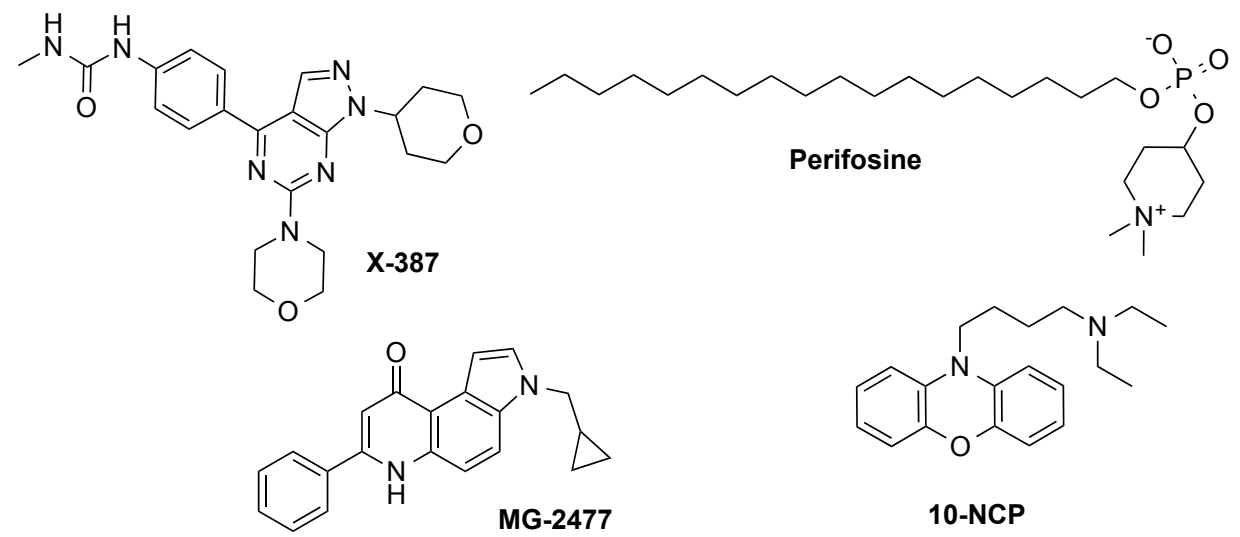

Figure 6. mTOR inhibitor X-387 and AKT inhibitors Perifosine, MG-2477 and 10NCP

In summary, pan mTOR inhibitors have shown potent effects on mTOR signalling pathway compared to the weak rapamycin. Moreover, their anticancer effect is usually superior due to the concomitant inhibition of rapamycin-insensitive mTORC2 activity in addition to mTORC1 inhibition. Although the current interest in the development of mTOR inhibitors is mainly focused on cancer treatment, their use as autophagy inducers in research or with therapeutic aims, such as the treatment of neurological disorders, is increasing. However, apart from regulating autophagy, the mTOR signalling also controls several other cellular processes such as protein synthesis and consequently, mTOR inhibition may be important sideeffects that should be also considered,.

Table 2. Activities ( $\left.\mathrm{IC}_{50}, \mathrm{nM}\right)$ of the reported pan-mTOR inhibitors. a) kinase in vitro data was obtained with precipitated proteins; b) mTOR inhibition data was obtained in vitro assay; c) Cellular mTOR inhibition data obtained using a Förster resonance energy transfer (FRET)-based by monitoring the phosphorylation of S6K1 using a phospho specific antibody.

\begin{tabular}{|c|c|c|c|c|}
\hline & \multicolumn{4}{|c|}{$\mathrm{IC}_{50}(\mathrm{nM})$} \\
\hline & \multicolumn{3}{|c|}{ PI3K } & \multirow{2}{*}{ mTOR } \\
\hline & $\mathrm{p} 110 \alpha$ & $\mathrm{p} 110 \beta$ & $\mathrm{p} 110 \gamma$ & \\
\hline PP242 a,44 & 1960 & 2200 & 102 & 8 \\
\hline PP30 a,44 & 3000 & 5800 & 680 & 80 \\
\hline Torin b,c, 47 & \multicolumn{3}{|c|}{300} & 0.27 \\
\hline Torin2 b,c, 49 & \multicolumn{3}{|c|}{200} & 0.25 \\
\hline $\begin{array}{c}\mathrm{Ku} 0063794 \\
\text { c, } 51\end{array}$ & $>10000$ & $>10000$ & $>10000$ & 10 \\
\hline AZD8055 c,52 & $>10000$ & $>10000$ & $>10000$ & 0.8 \\
\hline X-387 57 & 163 & $>300$ & $>300$ & 15 \\
\hline WYE-357 c,55 & $>500$ & $>500$ & $>500$ & 5 \\
\hline
\end{tabular}

\section{AKT inhibitors}


Chemical compounds can also indirectly affect mTOR signaling and consequently autophagy by acting on upstream targets suchs as AMPK (Adenosine MonoPhosphate-activated protein kinase), tuberous sclerosis 2 (TSC) or the kinase AKT.

mTOR is a target for AKT, therefore AKT inhibition supresses mTOR activation that also results in autophagy induction. As a result, several AKT inhibitors have been reported as autophagy modulators and will be summarized below.

Perifosine is an alkylphospholipid that induces autophagy via AKT inhibition, ${ }^{58}$ although additional studies have suggested that this effect may be facilitated by the degradation of major components of the mTOR complex, including mTOR, raptor and rictor. ${ }^{9}$ The tubulin polymerization inhibitor MG-2477 was also shown to induce protective autophagy in A549 cells probably due to blockage of AKT. ${ }^{60}$ Another known AKT inhibitor with activity as autophagy inducer in neuronal cells is the N-substituted phenoxazine 10-NCP (Figure 6). ${ }^{61}$ Some related compounds such as trifluoroperazine, promazine, chlorpromazine or trifluoropromazine, have showed also similar effect. However, additional studies showed that these compounds may act in a AKT- and mTOR-independent manner and therefore the exact mechanism of action is unknown yet. ${ }^{62}$ As example, trifluoroperazine is also a known calmodulin inhibitor and may exert its function through the $\mathrm{Ca}^{2+}$ signalling pathway. ${ }^{63}$

\section{AMPK activators}

AMPK (Adenosine MonoPhosphate-activated protein kinase) induces autophagy by targeting mTORC1 or tuberous sclerosis 2 or by direct phosphorylation of Ulk (the Agt1/Ulk complex is located at the initial isolation membrane and required for autophagosome formation). ${ }^{64}$ Hence, several AMPK activators have also been reported as autophagy inducers.

The antidiabetic drug metformin is one of the AMPK activators widely used autophagy inducer. ${ }^{65}$ Moreover, metformin can also extend life span in mice. ${ }^{66}$ However, recent results suggest that metformin may inhibit mTOR-signalling by processes that do not depend on AMPK (Figure 7). ${ }^{67}$ The natural product Rottlerin, isolated from Mallotus philippinensis, can be also included in this category. Although Rottlerin is as protein kinase $\mathrm{C}$ delta inhibitor, it can also induce autophagy in a PKC-independent manner ${ }^{68,69}$ probably through AMPK activation and proteasome inhibition..$^{70}$ Previous studies have also shown the activity of Rottlerin as well as known drugs such as Niclosamide, Amiodarone and Perhexiline in autophagy induction suggesting their implication as mTORsignalling inhibitors. ${ }^{68}$ More recently, additional studies have suggested that Niclosamide $(10 \mathrm{mM})$ acts as a protonophore and its selective effect on mTORC1 is caused by the acidification of the cytoplasm acidification rather than by the direct inhibition of the mTORC1.71 

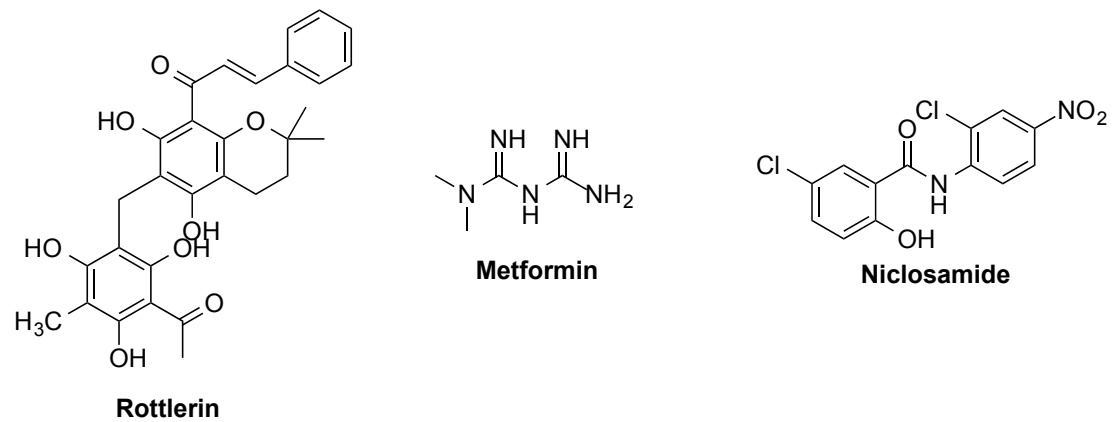

Figure 7. Structures of autophagy inducers suggested to act on AMPK and the protonophore Niclosamide.

\section{Miscellaneous.}

Due to the crucial role of the mTOR-signalling cascade in the regulation of autophagy, when autophagy inducers with unknown target are identified, the implication of the mTOR network is usually investigated in order to discard or confirm its involvement. As a result, some autophagy inducers have been proven to function through the mTOR pathway albeit with a yet unknown target. This is the case of several Farnesyltransferase Inhibitors (FTI), ${ }^{72} \Delta^{9}$-tetrahydrocannabinol ${ }^{73}$ and phenethylisothiocyanate (PEITC). ${ }^{74}$ The related benzyl ITC also promotes autophagy induction in an mTOR-depending manner with a yet unknown mechanism of action. ${ }^{75}$ Another example is compound $\mathrm{C}$, also called Dorsomorphin, an AMPK inhibitor that also functions as autophagy inducer. However, its mechanism of action is probably AMPK-independent and mediated by AKT suppression and subsequent downregulation of mTOR-signalling (Figure 8). ${ }^{76}$
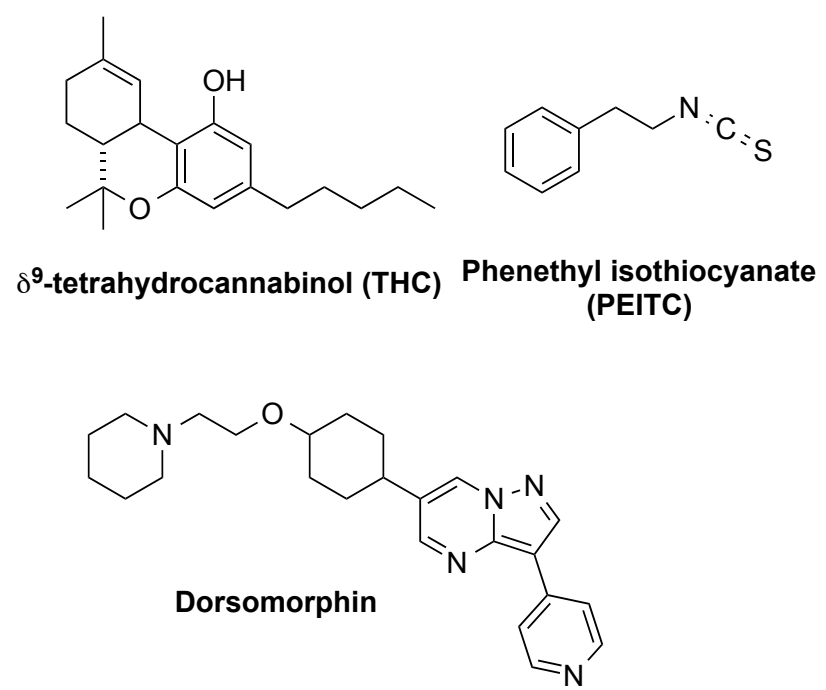

Figure 8. Chemical structures of the autophagy inducers $\delta^{9}$-THC, PEITC and Dorsomorphin.

In a collaborative work from the groups of Stuart Schreiber and David Rubinsztein, novel autophagy inducers with a yet unknown mechanism were also identified from the HTS of a chemical library formed by 50,729 compounds. Three compounds of this library or analogues synthesized thereof (SMER10, SMER18, SMER28) were able to increase cellular autophagy as revealed by an increase in the clearance of the protein Huntingtin, an important autophagy substrate whose accumulation causes the Huntington disease. The active compounds include the 
aminopyrimidones SMER10 and SMER10a lacking the amino group at 3 position, the vinylogous amide SMER18 and the bromo-substituted quinazoline SMER28, obtained by microwave-assisted alkylation of 4-chloroquinzaoline with allylamine (Figure 9). The exact mechanism of action of the SMER compounds is not clear yet. The available data suggest that they act in a mTOR-independent fashion, although they may also act on a yet unknown component of the mTOR pathway. Independently of their mechanism of action, these scaffolds may serve as a good starting point for the synthesis of more potent and selective autophagy inducers. ${ }^{77}$<smiles>Nn1cnc2c(c1=O)C1(CCCC1)Cc1ccccc1-2</smiles>

SMER 10<smiles>O=c1[nH]cnc2c1C1(CCCC1)Cc1ccccc1-2</smiles>

SMER 10a<smiles>C/C(=C/C(=O)c1ccc(Cl)cc1)Nc1cccc(O)c1</smiles>

SMER18<smiles>C=CCNc1ncnc2ccc(Br)cc12</smiles>

SMER28

Figure 9. Small molecules enhancers of rapamycin activity (SMER) detected in a HTS assay.

STF-62247 is another synthetic compound identified from the screening of a 64,000 compound-library. When tested in renal cell carcinomas (RCC) containing or lacking the von Hippel-Lindau (VHL) tumor suppressor gene, STG-62247 induced autophagy in both cell lines and selective lethality only in VHL-deficient renal cancer cells. The suggested targets for STF-62247 are proteins involved in Golgi trafficking. ${ }^{78}$ The synthesis of STF-662247, which contains a pyridylanilinothiazole scaffold bearing a methyl subtitutent on the aniline ring, can be seen in scheme 7. The synthesis relies on the Hantzsch thiazole synthesis, condensing pyridylbromoketones with phenylthioureas. The required 4-pyridyl-2bromoacetone was prepared from 4-acetylpyridine by acid-catalyzed bromination with bromine in acetic acid and the substituted phenylthiourea could be prepared in moderate yields from the corresponding aniline using $\mathrm{NH}_{4} \mathrm{SCN}$ or upon reaction of benzoyl isocyanate and the substituted aniline followed by hydrolysis (Scheme 7). ${ }^{79}$ A natural compound, Englerin A (Scheme 7), has also shown selective effect on RCC upon apoptosis and autophagy induction probably due to AKT and Erk inhibition, although the direct target is still unknown. ${ }^{2}$ 


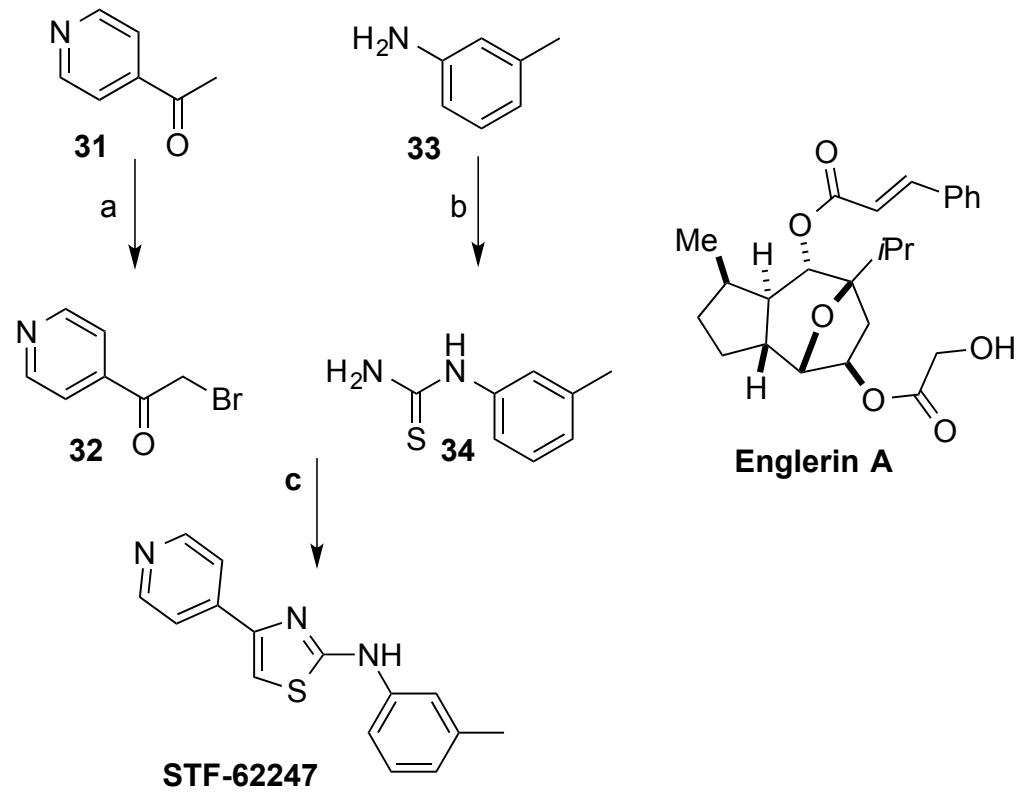

Scheme 7. Structure of STF-62247 and Englerin A; Reagents and conditions: a) $\mathrm{Br}_{2}, 30 \% \mathrm{HOAc} / \mathrm{HBr},-40 \mathrm{C} 1 \mathrm{~h},-75^{\circ} \mathrm{C} 1 \mathrm{~h}$; b) $\mathrm{NH}_{4} \mathrm{SCN}, \mathrm{m}$-toluidine in $1 \mathrm{M} \mathrm{HCl} 100^{\circ} \mathrm{C}$, 16h; or Benzoyl chloride, $\mathrm{NH}_{4} \mathrm{SCN}$, acetone, $15 \mathrm{~min}$, reflux; m-toluidine, $30 \mathrm{~min}$, reflux; then aqueous $\mathrm{NaOH}(10 \% \mathrm{w} / \mathrm{v})$; c) EtOH, reflux, $1 \mathrm{~h}$.

Oxidative stress or the intracellular production of reactive oxygen species (ROS) can also induce autophagy. ${ }^{80}$ Under starving condition, cells generate ROS what results in autophagy induction by mechanisms involving mTOR downregulation, AMPK activation, upregulation of Beclin-1 expression, changes in the levels of the autophagy adaptor protein p62 or directly oxidation and inactivation of the catalytic cysteine in the protease Atg $4 .{ }^{11}$ ROS can also be generated upon treatment with external agents. The sphingolipid analog saphingol, ${ }^{81}$ arsenic trioxide, ${ }^{82}$ resveratrol, ${ }^{83}$ and vorinostat ${ }^{84}$ among others have been shown to induce autophagy through intracellular ROS generation (Figure 10). ${ }^{85}$ Resveratrol ${ }^{54}$ can be also included in this category although in the case of this natural product its direct effect on the mTOR/AMPK pathway has been also suggested. ${ }^{44}$ Dihydroceramide (DHCer) the precursor of the signalling lipid ceramide (Cer), may also play a key role in the mechanism of ROS as autophagy inducer. Hence, it has been shown that autophagy induction upon treatment with resveratrol 86,87 is correlated with an increase in DHCer levels. This effect could be mimicked by the increase of DHCer levels using the DHCer desaturase and COX-2 inhibitor Celecoxib. ${ }^{88}$ Other DHCer desaturase inhibitors XM462 ${ }^{86}$ and Fenretinide ${ }^{89}$ have also shown to induce autophagy, although in this case the implication of ROS is not fully clear.

Another relevant sphingolipid, ceramide, has been extensively involved in the regulation of autophagy, albeit with a yet unclear mechanism. Ceramide induction of autophagy may have a protective or lethal effect for the cell..$^{90}$ Ceramide's role in autophagy may be mediated by targeting protein phosphatase 2A (PP2A) and thus blockage of Akt phosphorylation, ${ }^{91}$ AMPK activation, by modulating Beclin-1 expression ${ }^{92}$ or via selective targeting of LC3-II containing autophagolysosomes to mitochondria (Figure 10). ${ }^{93}$ Apart from the sphingolipids, many other lipids have 
also been implicated in autophagy regulation. ${ }^{94}$ This is the case of 2-hydroxyoleic acid, which has been proven to induce autophagic cell death in human glioma cells. ${ }^{95}$
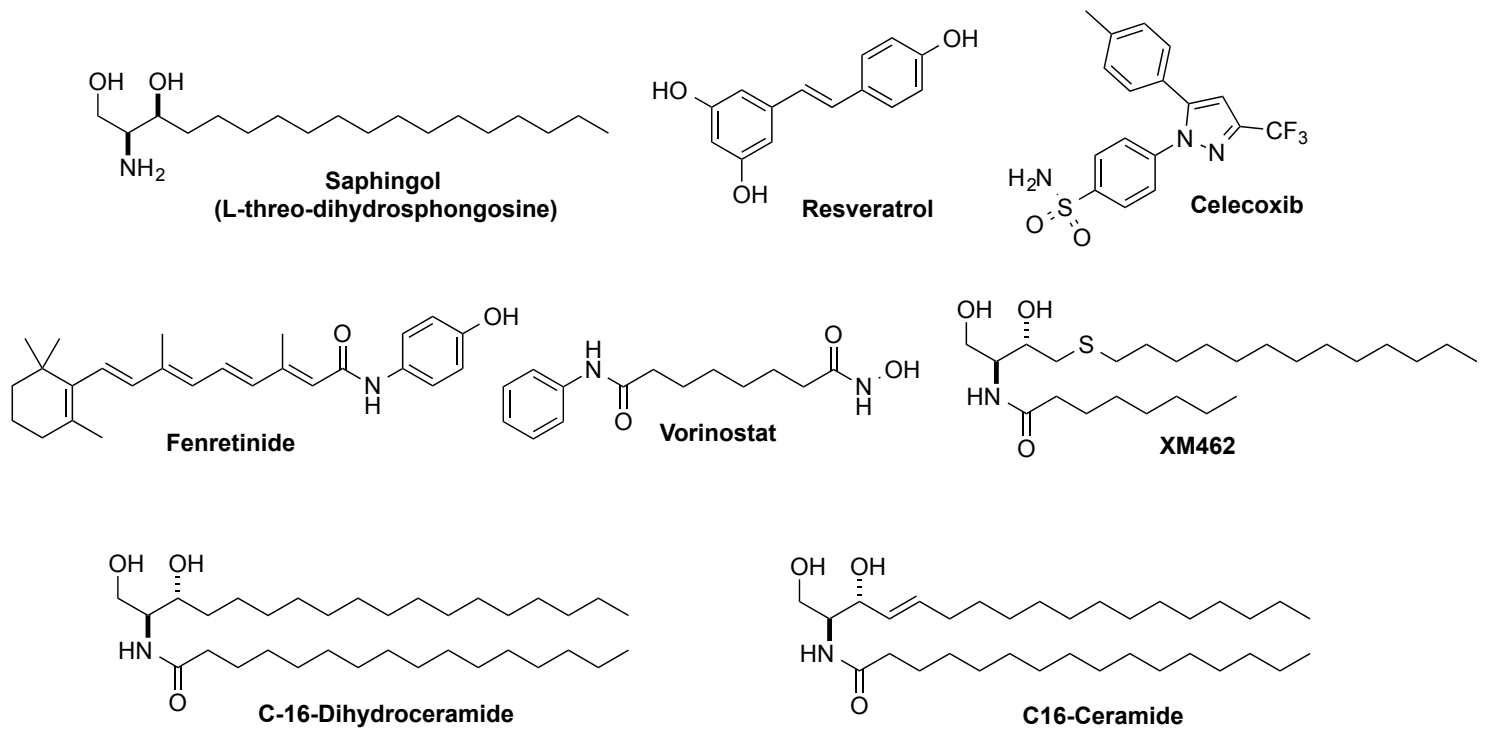

Figure 10. Chemical structures of additional autophagy inducers. Some of these compounds have been suggested to act via generation of reactive oxygen species (ROS).

In summary, important efforts have been done for the identification of chemical tools modulating autophagy acting directly or indirectly on the mTOR pathway. Although most of the described compounds are mainly useful tools for basic research, their activity in several disease is also being investigated. ${ }^{5}$ However, apart from their effect on autophagy most of these compounds have additional cellular effects. Consequently, there is still a strong need for the development of more selective autophagy inducers.

\section{mTOR-independent pathway}

Although the mTOR-dependent autophagy is the best-characterized system, recent investigations have shed light on the mechanisms regulating mTOR-independent autophagy. Most of the chemical modulators affecting this process act on the inositol or the calcium signaling pathway.

The inositol signalling pathway is an important regulator of this process. It has been shown that an increase of the inositol 1,4,5-triphosphate ( $\left.\mathrm{IP}_{3}\right)$ levels negatively regulates autophagy (Figure 1). Therefore, compounds causing the lowering of $\mathrm{IP}_{3}$ levels function as inducers of autophagy. ${ }^{20}$ This is the case of the mood-stabilizing drugs lithium ion, valproic acid and carbamazepine, ${ }^{96}$ which inhibits the inositol monphosphatase (IMPase) and supresses the uptake of inositol by cells (Figure 11). These are commonly used drugs that may have promising applications as autophagy inducers.

Regulation of calcium signalling is an additional control point. An influx of $\mathrm{Ca}^{2+}$ into the cytoplasm activates calpains which in turn inhibits autophagy. Hence, L- 
type $\mathrm{Ca}^{2+}$ channel blockers such as verapamil, loperamide, nimodipine, nitrendipine and amiodarone and calpain inhibitors such as calpastatin have been also described as autophagy inducers (Figure 11). ${ }^{97}$ Additional autophagy inducers acting on calcium signalling have emerged from HTS assays. As example, fluspirilene, trifluoperazine, a known calmodulin inhibitor, ${ }^{63}$ pimozide, niguldipine, nicardipine, and penitrem A were identified from a 480 compound library employing a HT image-based screening assay followed by a cellular assay to measure protein degradation. Although these identified drugs are indicated for different diseases they all share a common activity as calcium signalling blockers. ${ }^{98}$

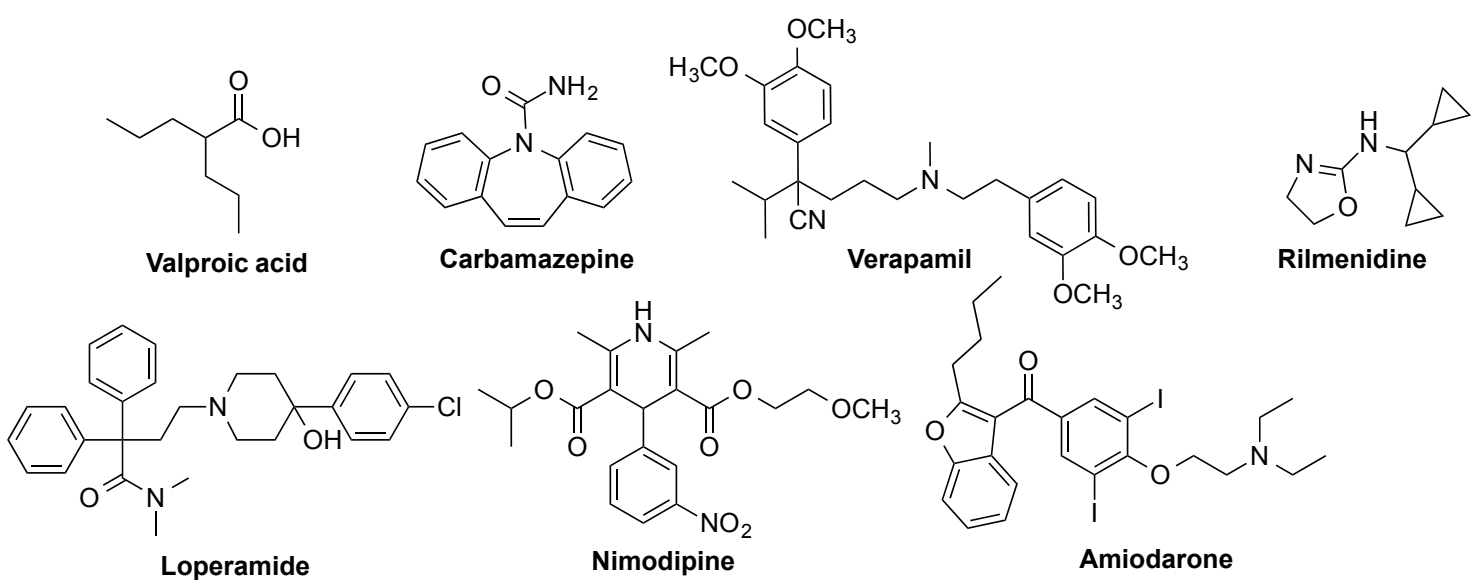

Figure 11. mTOR-independent inducers of autophagy.

A screening of FDA approved drugs to search for autophagy inducers revealed Rilmenidine, an hypertensive agents that acts on imidazoline receptors and also reduces cAMP levels. This compound showed promising results in a mouse model of the neurodegenerative Huntington disease and its effect is currently being investigated in clinical trials. ${ }^{97,} 99$

\section{INDUCERS OF CHAPERONE-MEDIATED AUTOPHAGY}

Although most of the work in the search for chemical modulators of autophagy has been directed to target macroautophagy, recent efforts have also been made for the selective target of chaperone-mediated autophagy (CMA). ${ }^{100,} 101$ CMA is involved in the progression of neurodegenerative diseases and a decline in CMA activity with age seems to be strongly correlated with age-related disorders. ${ }^{102}$ There is currently a lack of selective modulators of CMA, mainly due to the fact that the cellular pathways controlling this pathway are nearly unknown. ${ }^{100} \mathrm{~A}$ recent work has however shed light on this process by identifying a novel and selective target for CMA, the retinoic acid receptor $\alpha$ (RAR $\alpha)$, that has enabled the synthesis of RAR $\alpha$ antagonists that resulted in selective CMA induction without affecting macroautophagy. ${ }^{101}$

The natural substrate for RAR $\alpha$ receptor is all-trans retinoic acid (ATRA, Figure 12). Since previous results demonstrated that ATRA does not affect macroautophagy and that the effect of ATRA on CMA was only dependent on RAR $\alpha$, it was envisaged that ATRA derivatives acting as RAR $\alpha$ antagonists should 
result in selective activators of CMA without affecting other autophagy pathways. To this end, a small library of 29 compounds based on retinoic acid derivatives was designed and synthesized. Modifications at the $\mathrm{C} 4$ position at the hydrophobic ring were incorporated to prevent its oxidation. Derivatives were grouped in four major families: aminonitrile retinoids (AmR), boron-aminonitrile retinoids (BAmR), guanidine retinoids (GR) and atypical retinoics (AR) (Figure 12). After toxicity and cellular studies, three compounds (AR7, GR1 and GR2) were identified as inducers of CMA, thus confirming that the selective activation of CMA can be achieved by retinoic acid derivatives and showing the potential selective targeting of autophagy processes using small-molecules.<smiles>CC1=C(/C=C/C(C)=C/C=C/C(C)=C/C(=O)O)C(C)(C)CCC1</smiles>

all-trans retinoic acid (ATRA)<smiles>[R]C1([R])CC(C)=CC(=Cc2ccc(C(=O)NC(=N)N)cc2)C1</smiles>

GR1 $\mathrm{R}_{1}=\mathrm{R}_{2}=\mathrm{CH}_{3}$

GR2 $R_{1}=R_{2}=H$<smiles></smiles>

C4 BAmR1 $\mathrm{Ar}=\mathrm{Ph}$ C5 BAmR2 $\mathrm{Ar}=4-\mathrm{F}-\mathrm{Ph}$<smiles>[R]c1cc([R])c(NC(C#N)C2=C(C)CCCC2(C)C)cc1[R]</smiles><smiles>[R]c1ccc(C2=Nc3cc([R2])c([R])cc3OC2)cc1</smiles>

\begin{tabular}{llll} 
& $\mathrm{R}_{1}$ & $\mathrm{R}_{2}$ & $\mathrm{R}_{3}$ \\
\cline { 2 - 4 }$\alpha$ AmR1 & $\mathrm{H}$ & $\mathrm{H}$ & $\mathrm{H}$ \\
$\alpha$ AmR2 & $\mathrm{NO}_{2}$ & $\mathrm{H}$ & $\mathrm{H}$ \\
$\alpha$ AmR3 & $\mathrm{F}$ & $\mathrm{H}$ & $\mathrm{H}$ \\
$\alpha$ AmR4 & $\mathrm{H}$ & $\mathrm{H}$ & $\mathrm{H}$ \\
$\alpha$ AmR5 & $\mathrm{H}$ & $\mathrm{OH}$ & $\mathrm{NO}_{2}$ \\
$\alpha$ AmR6 & $\mathrm{OH}$ & $\mathrm{H}$ & $\mathrm{H}$ \\
$\alpha$ AmR7 & $\mathrm{CH}_{2} \mathrm{CH}_{2} \mathrm{OH} \mathrm{H}$ & $\mathrm{H}$ \\
$\alpha$ AmR8 & $\mathrm{OCH}_{3}$ & $\mathrm{H}$ & $\mathrm{H}$ \\
$\alpha$ AmR9 & $\mathrm{Cl}$ & $\mathrm{H}$ & $\mathrm{H}$ \\
$\alpha$ AmR10 & meth. carbox H & $\mathrm{H}$ \\
$\alpha$ AmR11 & \multicolumn{2}{l}{ Boron ester $\mathrm{H}$} & $\mathrm{H}$
\end{tabular}

Figure 12. ATRA and ATRA derivatives have been tested for their activity as RAR $\alpha$ receptor antagonists and as inducers of chaperone-mediated autophagy.

\section{AUTOPHAGY INHIBITORS}

Most of the autophagy modulators reported up to now are autophagy inducers acting mainly on the mTOR-signalling pathway. Nevertheless, several autophagy inhibitors have also been described and will be summarized in this section. Most of the reported inhibitors act in a non-specific way on lysosomal function or on the fusion step with autophagosomes. However, recent work has enabled the design and identification of selective autophagy inhibitors that act on particular protein targets. Despite these promising results, many efforts are still required in this field to obtain selective and potent autophagy inhibitors. 
There are several possible regulation steps on autophagy and have been therefore considered as possible targets to inhibit this process. The best-characterized ones are the lipid kinases PI3K. The formation of the initial phagophore requires the presence of phosphatidylinositol-3-phosphate (PI3P) and therefore, PI3K inhibitors blocking the generation of this phosphorylated lipid can function as autophagy inhibitors.

\section{PI3K Inhibition}

As mentioned above, the kinases PI3K have different roles in autophagy regulation. Class I PI3K negatively regulates this process and consequently, class I PI3K inhibitors are autophagy inducers. However, class III PI3K is a positive regulator of autophagy with a crucial role in autophagosome cargo sequestration and therefore, class III PI3K inhibitors cause an inhibition of autophagy. Since class III is downstream of class I, unspecific or general PI3K inhibitors have as a final effect the inhibition of autophagy. Remarkable examples of this activity class compounds are 3-methyladeninde, wortmannin and LY294002 (Figure 13). ${ }^{103}$

Wortmannin is a natural product that irreversibly blocks PI3K upon formation of an enamine at C20 with a Lys residue of the protein. ${ }^{104}$, 105 LY294002, a morpholino-derivative of quercetin, is a synthetic pan PI3K inhibitors developed by Lilly that blocks all the kinase classes but requires high concentrations. Although is 500 times less potent than Wortmannin, its improved chemical stability has promoted its wide use. X-ray co-crystal structure of LY294002 with PI3K $\gamma$ has been elucidated showing that the interaction relies on a hydrogen bond between the morpholino oxygen and the backbone amide of Val 882.104 Neither Wortmannin nor LY294002 have progressed to clinical trials due to their poor pharmacokinetic properties and high toxicity although they have been widely employed as tools in basic research. However, special caution should be taken when using these unspecific PI3K inhibitors, because due to the similarity of PI3K with mTOR, they also inhibit mTOR signalling or other kinases giving in some cases confusing outputs. ${ }^{106}$ More recently SF-1126 (Semafore), a prodrug of LY294002 conjugated to a tetrapeptide (RGDS, that stands for Arginine-glycineaspartic acid-serine), has been described. This peptide is a known binding motif for integrin located in the tumour vasculature. The conjugated SF-1126 is directed to this region and once there specifically inhibits PI3K-dependent angiogenesis in the tumour. ${ }^{107}$ Another general PI3K inhibitor widely employed as autophagy inhibitor in basic research is 3-methyladenine (3-MA). Although 3-MA inhibits both class I and class II PI3K, at the $10 \mathrm{mM}$ concentration typically used for inhibiting autophagy it has preferentially for class III PI3K. However its dual effect may cause complicated outputs as 3-MA inhibits permanently class I and only transiently class III that after long treatment causes autophagy induction instead of inhibition. ${ }^{108}$ Although class III inhibitors are widely used as autophagy inhibitors one should take into account that apart from the poor selectivity of the mentioned inhibitors, as PI3K, both class I and class III, regulate several cell signalling and membrane trafficking processes, these are not specific autophagy inhibitors and many other cellular processes may be also affected. Hence, until more specific modulators are found, results obtained using these compounds should be carefully taken and validated using genetic approaches. 
<smiles>COC[C@H]1OC(=O)c2coc3c2[C@@]1(O)C1=C(C3=O)C2CCC(=O)C2(C)CC1OC(C)=O</smiles>

Wortmannin<smiles>O=c1cc(N2CCOCC2)oc2c(-c3ccccc3)cccc12</smiles><smiles>Cn1cnc(N)c2ncnc1-2</smiles>

3-Methyladenine

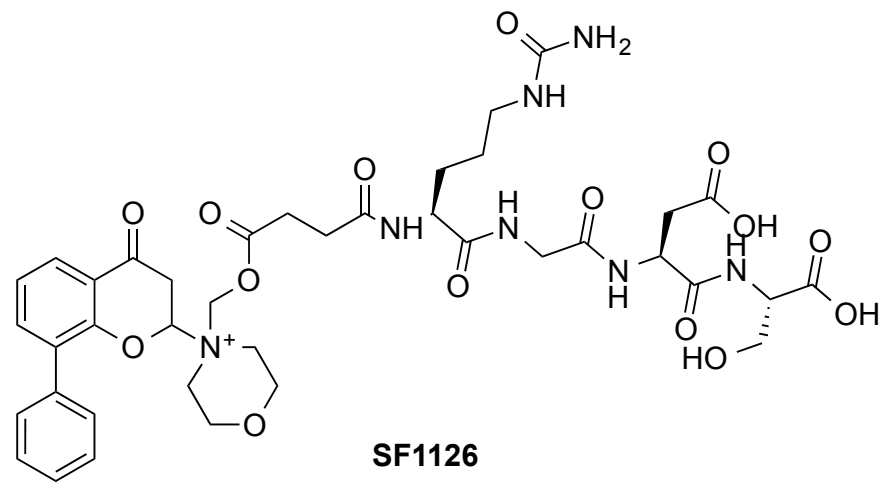

Figure 13. Pan-PI3K inhibitors.

Another interesting target for the development of autophagy inhibitors is the class III PI3K Vps34. ${ }^{109}$ A complex containing Beclin1, Vps15 and Vps34 is essential for the initial formation of the phagophore and therefore Vps34 is considered an interesting target to obtain autophagy inhibitors.

Vps34 (whose name is derived from vesicle-mediated vacuolar protein sorting) was first identified in yeast and is also found in mammals were it is the only class III PI3K. The crucial role of this lipid kinase is proven by the fact that cells lacking the mammal orthologs of Vps34 can not undergo autophagic degradation and starvation-induced autophagosome formation. ${ }^{109}$ Recently the X-ray crystal structure of Vps34 has been described revealing that the ATP binding pocket in Vps34 is significantly smaller than the one in class I PI3K, which may has hampered the search for specific Vps34 inhibitors. ${ }^{110}$ On basis of this structural information, specific Vps34 inhibitors could be obtained starting from the phenylthiazole PIK-93, a known PI4K inhibitor, and following a structure-based approach. Briefly, an increase of the steric bulk of PIK-93 by replacing the chloro substituent with a methoxy group yielded compound 35, which retained Vps34 activity but lost activity for class I PI3K. Additional modification oriented toward the hinge region differences existing between Vps34 and PI3K yielded PT210, containing a cyclopentanecarboxamide with remarkable selectivity for Vps34 (450 $\mathrm{nM}$, vs $4 \mathrm{mM}$ for PI3K). ${ }^{110}$ Synthesis of PT210 starts from arylketone 36. Installation of the sulfamido group followed by selective $\alpha$-bromination ${ }^{111}$ afforded the intermediate 38, which via a thiazole Hantsch synthesis yielded the final compound PT210 (Scheme 8). This important work has open the door to the design of potent and selective Vps34 inhibitors that may be promising starting points both in basic research and in therapy. 


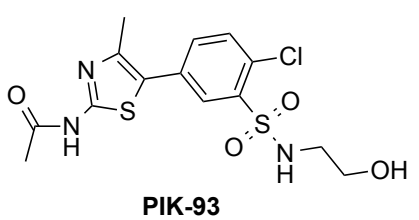

PIK-93

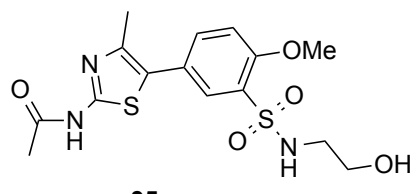

35

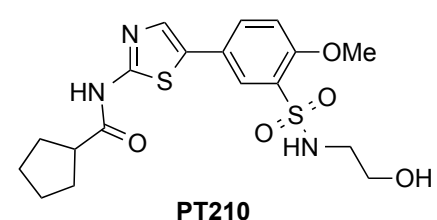

PT210<smiles>COc1ccc(CC(C)=O)cc1</smiles>

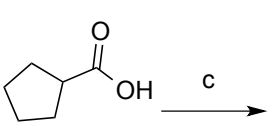

39

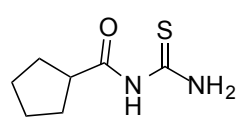

40

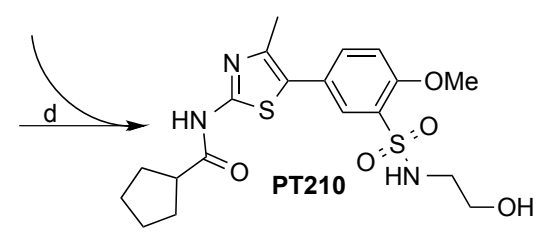<smiles></smiles>

KU-55933
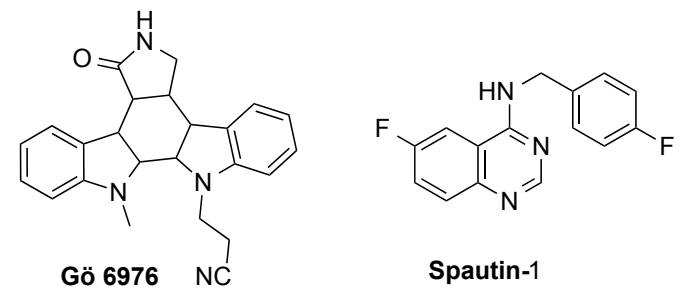

Scheme 8. Reagents and conditions: a) $\mathrm{HSO}_{3} \mathrm{Cl}, 2.5 \mathrm{~h}$; ethanolamine, THF, o/n, rt, 21\%; b) 2-carboxyethyltriphosphoniumperbromide, THF, $1 \mathrm{~h}$ rt $72 \%$; c) Oxalylchloride, $72^{\circ} \mathrm{C}, 1 \mathrm{~h}$; thiourea, toluene, reflux, 18h, 57\%; d) EtOH, reflux, $1 \mathrm{~h}$, $75 \%$.

Other Vps34 inhibitors, KU-55933 and Gö6976, have been recently identified from a HTS assay aimed to find inhibitors of rapamycin-induced autophagy (Scheme 8). KU-55933 was initially described as inhibitor of ataxia telangiectasia-mutated (ATM) ${ }^{112}$ and Gö6976 $6^{113}$ as a broad-spectrum protein kinase C inhibitor. However, further validation of their mode of action confirmed that these compounds inhibit autophagy and the kinase Vps34 at low $\mu$ molar concentration without affecting class I PI3K-mediated signalling. ${ }^{114}$

More recently, another autophagy inhibitor termed Spautin-1 has been described. This compound promotes the degradation of the Vps34-containing complex by inhibiting the ubiquitin-specific peptidases USP10 and USP13 which are in charge of Vps34 deubiquitination. The blockage of these peptidases results in the increase ubiquitination and degradation of class III PI3K complexes through the proteasomal pathway which results in autophagy inhibition. ${ }^{115}$

Almost all the reported mTOR-modulating compounds induce autophagy through inhibition of this signalling cascade. Contrarily, the recently described, MHY1485 seems to inhibit autophagy via activation of mTOR-signalling, acting either directly on mTOR kinase or upstream of this protein. ${ }^{116}$ MHY1485 contains a dimorpholino triazine scaffold and was identified from a compound library of trisubstituted triazines. The synthesis of MHY1485 is depicted in Scheme 9 and relies on the reaction of cyanuric chloride with nucleophiles, i.e initial substitution with morpholine (43) followed by reaction with 4-nitroaniline in the presence of 


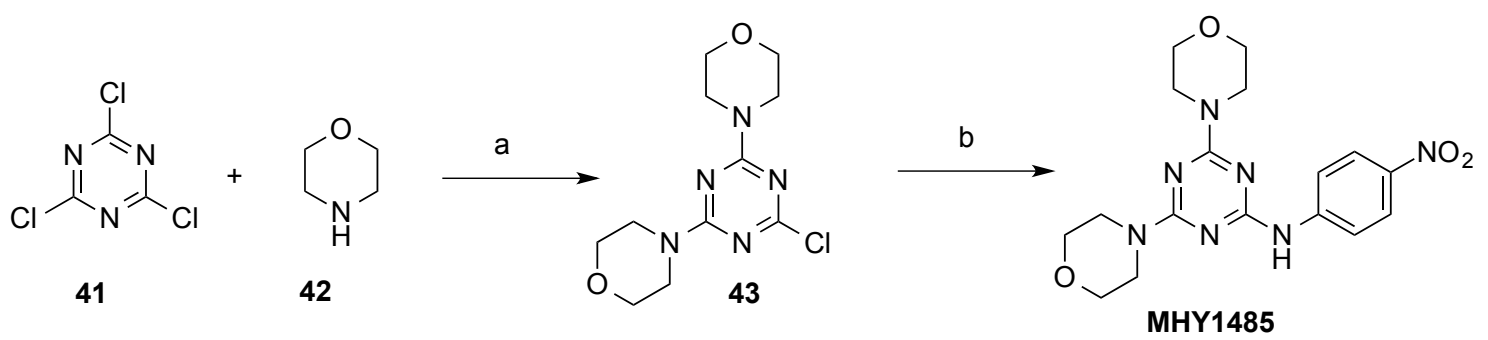

Scheme 9. Reagents and conditions: triethylamine, acetone $-10^{\circ} \mathrm{C}, 1 \mathrm{~h} ; 4-$ nitroaniline, $\mathrm{K}_{2} \mathrm{CO}_{3}$, DMF, 4 h reflux.

\section{Autophagy machinery}

Once the phagophore is formed, this structure will elongate and finally close to form the autophagosome, thereby engulfing all the material to be degraded (Figure 1). This process is controlled by several autophagy related genes and proteins (Atg) that constitute the so-called autophagy machinery. ${ }^{118}$

More than 20 Atg proteins have been described since they were first identified in yeast in which is considered a key breakthrough in autophagy research. Due to their crucial role in the elongation, closure of the autophagy and its fusion with the lysosome, these proteins have also been considered interesting targets for the development of autophagy inhibitors. One of the best-characterized Atg proteins is the bona-fide autophagy marker Atg8 (or its mammal ortholog LC3). Although the exact role of LC3 is not completely clear yet, it is known that the correct location of LC3 in the autophagosome membrane is required for the correct functioning of the whole process (Figure 1). Membrane association of LC3 is mediated by its C-terminal lipidation with phosphatidylethanolamine (PE) thus generating the lipidated LC3-II in contrast with the cystosolic non-lipidated LC3-I (Figure 14). Recently, a fully lipidated LC3-II has been obtained by means of chemical ligation of a truncated expressed protein with a C-terminal lipidated peptide. ${ }^{119}$ It is envisaged that this semisynthetic protein will be an interesting tool to elucidate LC3-II role in the control and regulation of autophagy. LC3-II synthesis requires the activity of two ubiquitin-like systems. One conjugation systems is formed by Atg5, Atg12 and Atg16 and the second conjugation system involves Atg4, Atg7, Atg3. More precisely, the conversion of LC3-I in LC3-II and the subsequent delipidation of LC3-II require the activity of the cysteine protease Atg4, that has been therefore considered as a target for the identification of autophagy inhibitors (Figure 14). 

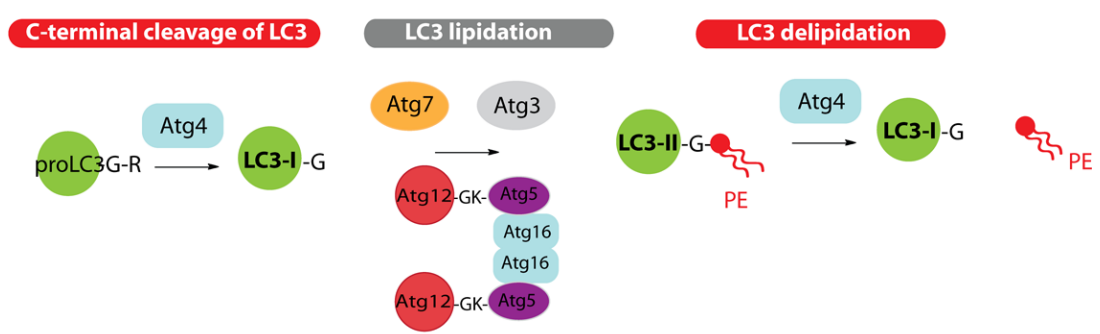

Figure 14. Correct localization and function of LC3 is crucial for the regulation of autophagy. LC3 needs to be associated to the autophagosome membrane to be active and this is mediated by $\mathrm{C}$-terminal lipidation with a $\mathrm{PE}$ unit mediated by several Atg proteins.

Some preliminary attempts to find selective inhibitors for Atg4 have been described. The first inhibitors have been identified upon screening of the LOPAC (Library of Pharmacologically Active Compounds) library and a compound library from Spectrum resulting in the identification of three compounds inhibiting Atg4 with $\mu \mathrm{M}$ activity (Figure 15). ${ }^{120}$ Additionally, Atg4 has also been suggested to be the target of reactive oxygen species that would act by modifying and inhibiting its catalytic cysteine. ${ }^{51}$

Apart from this crucial role in autophagosome elongation, LC3 and the yeast homolog Atg8 are also involved in the recruitment of specific cargo to the phagophore in a process known as selective autophagy. ${ }^{121}$ This is done via an LC3interacting region (LIR) motif present in proteins. The LIR motif is a $\mathrm{W} / \mathrm{F} / \mathrm{YxxL} / \mathrm{I} / \mathrm{V}$ sequence preceded by negatively-charged residues. The aromatic amino acids $(\mathrm{W} / \mathrm{F} / \mathrm{Y})$ can be a tryptophan, phenylalanine or tyrosine residues, while the aliphatic amino acids (L/I/V) can be leucine, isoleucine or valine residues and $\mathrm{X}$ is any other amino acid. ${ }^{122}$ Apart from this role in the sequestration of the cargo, several proteins belonging to the autophagy machinery, such as Atg3 or Atg13, also possess a LIR motif, that enables its correct localization in the phagophore upon LC3 interaction. Preliminary attempts suggest that these Atg8/LC3

interactions with LIR-containing proteins can be investigated as druggable targets. Recently, small molecule inhibitors of the Plasmodium falciparum Atg8-Atg3 interaction have been described upon screening of a library containing 352 small fragments. This screening led to the identification of pyrogallol (1,2,3trihydroxybenzene) that inhibits the Atg8-Atg3 interaction with an $\mathrm{IC}_{50}$ of $150 \mu \mathrm{M}$ (Figure 15). ${ }^{123}$ 
<smiles>O=C(O)c1cc(O)c(=O)c2c(O)c(O)ccc2c1</smiles><smiles>C[As](C)(=O)c1c(O)cc2c3c1OC(=O)C1C=C(O)C(O)=C(OC2=O)C31</smiles><smiles>Cc1c(O[C@@H]2O[C@H](CO)[C@@H](O)C(O)C2O)cccc1C1c2cccc(OC3O[C@H](CO)[C@@H](O)C(O)C3O)c2C(=O)C2C(O)CC(C(=O)O)CC2c2c(O)cc(C(=O)O)cc21</smiles>

Figure 15. Small molecules inhibitors of Atg4 and Atg8-Atg3 interaction identified in HTS assays.

\section{Inhibitors of lysosomal function}

The final step in the autophagy process is the fusion of the autophagosome with the lysosome thus delivering all the material that will be degraded by the lysosomal hydrolases. Hence, several inhibitors of autophagosome fusion with the lysosome or of lysosomal function have been widely investigated as autophagy inhibitors. Many proteins have been suggested to be implicated in the fusion of the autophagosomes with the lysosomes, and would be therefore additional interesting targets for the search of autophagy modulators. This is the case of the GTPase Rab7124 and the lysosome-associated membrane proteins LAMP1 and LAMP2. However, the exact role of these proteins and the possible implication of additional proteins is still unknown and this fact has hampered the search for specific inhibitors of autophagy acting on these proteins.

The majority of the autophagy inhibitors described act on lysosomal function. Although these inhibitors are interesting tools for research their non-specific effect on other cellular process makes them not preferable for therapeutic approaches. In addition, unspecific inhibition of cytosolic proteases should be also considered when analysing the results obtained using these inhibitors. Relevant examples of this compound class are the lysosomal proteases inhibitors E-64d, pepstatin A and leupeptin (Figure 16). E-64d is a membrane permeable derivative of the water soluble E-64. 125 E-64 was isolated from a culture of Aspergillus japonicus and irreversibly inhibits cysteine proteases without affecting serine proteases, except trypsin. The active moiety is the trans-epoxysuccinyl group that binds to a cystein at the active site forming a thioether. Leupeptin is also a membrane permeable inhibitor of serine and cysteine proteases including trypsin, plasmin, papain, calpain and cathepsin B. Pepstatin A is non-permeable inhibitor of aspartic proteases such pepsin, renin and several cathepsins and does not have any effect on thiol, neutral or serine proteases. ${ }^{126}$ Pepstatin contain the $\gamma$-amino acid statine and due to the low solubility and membrane permeability requires high dosis and long incubation times. These lysosomal proteases inhibitors can be used 
separately but it is usually recommended to use them in combination in order to achieve a complete blockage of lysosomal degradation (E64d, pepstatin $10 \mu \mathrm{g} / \mathrm{ml}$, Leupeptin $1 \mu \mathrm{g} / \mathrm{ml}$ ).<smiles>CCOC(=O)C1OC1C(=O)NC(CC(C)C)C(=O)NCCC(C)C</smiles>

E-64d<smiles>CC(C)C[C@H](NC(=O)[C@@H]1O[C@@H]1C(=O)O)C(=O)NCCCCNC(=N)N</smiles>

E-64<smiles>CC(C)CC(=O)N[C@H](C(=O)NC(C(=O)N[C@@H](CC(C)C)C(O)CC(=O)NC(C)C(=O)N[C@H](CC(C)C)C(O)CC(=O)O)C(C)C)C(C)C</smiles><smiles>CC(=O)NC(CC(C)C)C(=O)N[C@@H](CC(C)C)C(=O)NC(C=O)CCCNC(=N)N</smiles>

Figure 16. Chemical structures of the protease inhibitors E64d, Pepstatin and Leupeptin.

Inhibition of lysosomal degradation can also be achieved by raising the lysosomal $\mathrm{pH}$. Lysosomal acidic $\mathrm{pH}$ is generated by a vacuolar-type $\mathrm{H}+/$ - ATPase (V-ATPase). Hence, inhibition of this proton pump causes the neutralization of lysosomal $\mathrm{pH}$ that blocks its function and ultimately blocks the fusion of autophagosomes with lysosomes.127 Examples of this inhibitors class are the antibiotic macrolides Bafilomycin $\mathrm{A}^{128}$ or Concamycin (Figure 17). This type of inhibitors have also been widely used not only as autophagy inhibitors but also to prove the effect of novel identified inhibitors. Briefly, autophagy inhibition causes an accumulation of LC3-II that can be monitored. In order to discern if this accumulation is caused by a inhibition of this pathway or on the contrary by inhibition of autophagic flux (lysosomal function and fusion with autophagosomes) it is strongly recommended to compare the effect of the novel identified inhibitors alone or together with known inhibitors of lysosomal function. If the novel identified inhibitors are really autophagy inhibitors, the amount of LC3-II detected when combining these compounds and lysosomal inhibitors should increase compared to the treatment of the cells with the compounds alone. Low doses and short incubation time should be applied, otherwise Bafilomycin A1 also inhibits proteasome, endocytic trafficking and other cellular processes. ${ }^{129}$ 


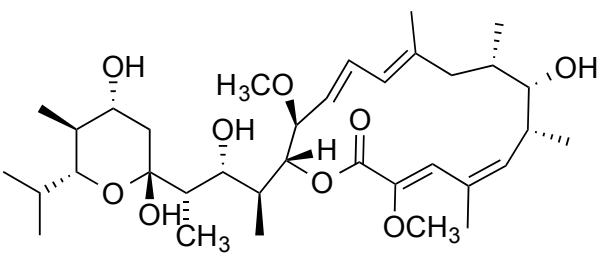

Bafilomycin A1

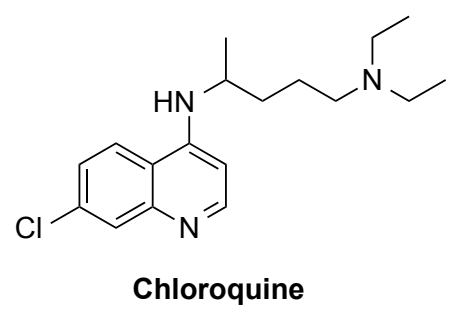

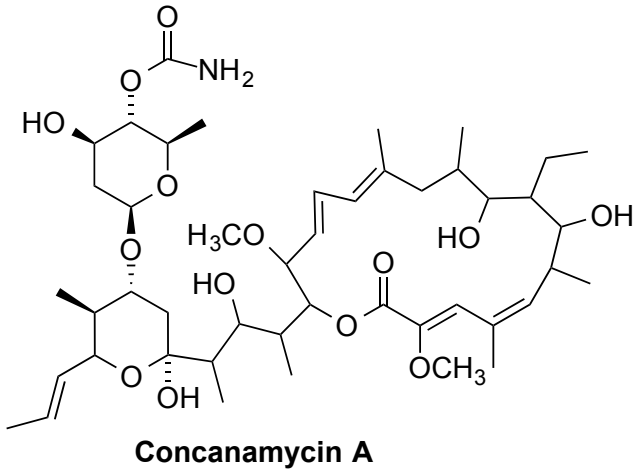<smiles>CCN(CCO)CCCC(C)Nc1ccnc2cc(Cl)ccc12</smiles>

Hydroxychloroquine

Figure 17. Inhibitors of autophagy that modify the lysosomal $\mathrm{pH}$.

Neutralization of lysosomal $\mathrm{pH}$ can also be achieved with lysosomotropic compounds, weak bases that preferentially accumulate in the lysosomes by an ion trapping mechanism. Weak bases may be partially deprotonated at phsysiological $\mathrm{pH}$ and the resulting deprotonated form is more membrane permeable than the protonated form. Once inside the lysosome, it gets protonated and thus trapped in this organelle. This protonation step causes a neutralization of lysosomal $\mathrm{pH}$ which leads to the inhibition of lysosomal enzymes that require acidic $\mathrm{pH}$ for its correct function and subsequently to inhibition of lysosomal protein degradation. ${ }^{130}$ The antimalaria Chloroquine (usually used at $50 \mu \mathrm{m}$ concentration), hydroxychloroquine and propylamine are the classical examples of this compound class, however these inhibitors need to be carefully used as they have additional effects such as the blocking of ATP production. Moreover, any treatment affecting lysosomal function can also affect other cellular processes such as endocytosis. Hence, caution should be taken with results obtained using this type of inhibitors.

Due to the lack of more specific inhibitors and despite its unspecific effect and the possible associated toxicity, this compound class has been widely used in basic research to block autophagy. Moreover, the first clinical trials based on autophagy inhibition are also focused on the use of these compounds. Thus, chloroquine and hydroxichloroquine are currently being investigated, together with several chemotherapeutic agents, in several ongoing phase I and phase II clinical trials aimed to explore if the outcome in cancer therapy can be improved via autophagy inhibition. ${ }^{131}$ However, recent studies have also suggested that chloroquine effect on cancer may be independent on autophagy induction. ${ }^{132}$

\section{Concluding remarks}

Although autophagy was first discovered approximately 40 years ago, the most important advances in this research field have been seen in the last decade. ${ }^{133}$ Today research on autophagy is a growing field with important therapeutic 
implications in several relevant processes such as neurodegenerative diseases, cancer, and age-related disorders. As a result, the search for small-molecules able to inhibit or induce autophagy is an emerging area of research. ${ }^{6}$

Despite these great advances seen in the last years, most of the existing autophagy modulators act still in a non-specific manner. Hence, potent autophagy inducers inhibiting the lipid kinase PI3K and/or the Ser/Thr mTOR kinase have been identified. These compounds overcome the limitations of rapamycin but still modulate many cellular processes in addition to autophagy. Analogously, most of known autophagy inducers are still inhibitors of lysosomal function. However, important preliminary work has already been done in the search of smallmolecules able to specifically modulate autophagy. Hence, the structural characterization of important autophagy regulators such as the lipid kinase Vps34 have enabled the synthesis of compounds that may serve as a basis for obtaining selective inhibitors of autophagy. Moreover, the discovery a decade ago of the autophagy machinery (Atg proteins) has also paved the way for the identification of novel targets that will be probably employed in a near future to obtain specific autophagy modulators.

Despite all these efforts, the identification of novel specific autophagy targets as well as the development of selective modulators of the known ones is still a challenging and demanding project. Many lines of research can be applied to achieve these goals. One approach is the better characterization of known targets facilitating the rational design of inhibitors as illustrated by the advances observed with the Vps34 kinase. Another strategy will be the development of HTS assays focused on specific autophagy targets. These approaches will be probably focused on the members of autophagy machinery and will require a prior characterization of the proteins involved in this process as well as their interactions with other proteins (i.e. Atg8-Atg3). Finally, the identification of novel targets and modulators by the combination of phenotypic assays, HTS of chemical libraries and proteomics studies it is also expected and will strongly contribute to a better knowledge in autophagy research. Independently of the strategy followed, these efforts will not be successful without the involvement of the chemical community. The work described in this report summarizes the recent efforts made by chemists and biologist in the development of small-molecules modulators of autophagy. The continuation of this long-term collaboration will be of particular importance in this promising research field and will definitely contribute to achieve these expected goals.

\section{Acknowledgements}

Funding from the Marie Curie Career Integration Grants, the Max Planck Society (Partner Groups) and the Ministerio de Economia y Competitividad (Grant CTQ2013-44334-P) is gratefully acknowledged. 


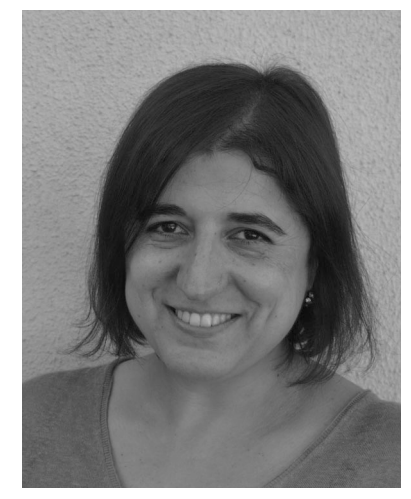

Gemma Triola (1976) gained her Ph.D. from the University of Barcelona in 2004 under the supervision of Prof. G. Fabriàs and Prof. A. Llebaria. She then moved to the Max Planck Institute of Molecular Physiology in Dortmund and joined the group of Prof. H. Waldmann first as a postdoctoral fellow and then as a group leader. Dr. G. Triola returned back to Spain in 2012 and was hired on a permanent position at the Institute of Advanced Chemistry of Catalonia (IQAC, Spanish Research Council (CSIC)). Her current research interests include the establishment of methods for protein modification, the characterization of lipid-protein interactions and the development of chemical biology tools for the study of autophagy.

\section{References}

1 P. Boya, F. Reggiori and P. Codogno, Nat. Cell Biol. 2013, 15, 713-720.

2 B. Ravikumar, M. Futter, L. Jahreiss, V. I. Korolchuk, M. Lichtenberg, S. Luo, D. C. Massey, F. M. Menzies, U. Narayanan, M. Renna, M. Jimenez-Sanchez, S. Sarkar, B. Underwood, A. Winslow and D. C. Rubinsztein, J. Cell Sci. 2009, 122, 1707-1711.

3 D. C. Rubinsztein, G. Marino and G. Kroemer, Cell 2011, 146, 682-695.

4 D. J. Metcalf, M. Garcia-Arencibia, W. E. Hochfeld and D. C. Rubinsztein, Exp. Neurol. 2012, 238, 22-28.

5 D. C. Rubinsztein, P. Codogno and B. Levine, Nat. Rev. Drug Discov. 2012, 11, 709730.

6 A. Fleming, T. Noda, T. Yoshimori and D. C. Rubinsztein, Nat. Chem. Biol. 2011, 7, 9-17.

7 F. Janku, D. J. McConkey, D. S. Hong and R. Kurzrock, Nat. Rev. Clin. Oncol. 2011, 8, 528-539.

8 J. D. Mancias and A. C. Kimmelman, Oncotarget 2011, 2, 1302-1306.

9 C. Selman, J. M. Tullet, D. Wieser, E. Irvine, S. J. Lingard, A. I. Choudhury, M. Claret, H. Al-Qassab, D. Carmignac, F. Ramadani, A. Woods, I. C. Robinson, E. Schuster, R. L. 
Batterham, S. C. Kozma, G. Thomas, D. Carling, K. Okkenhaug, J. M. Thornton, L. Partridge, D. Gems and D. J. Withers, Science 2009, 326, 140-144.

10 D. W. Lamming, L. Ye, D. M. Sabatini and J. A. Baur, J. Clin. Invest. 2013, 123, 980989.

11 D. J. Klionsky, F. C. Abdalla, H. Abeliovich, R. T. Abraham, A. Acevedo-Arozena, K. Adeli, L. Agholme, M. Agnello, P. Agostinis, J. A. Aguirre-Ghiso, H. J. Ahn, O. AitMohamed, S. Ait-Si-Ali, T. Akematsu, S. Akira, H. M. Al-Younes, M. A. Al-Zeer, M. L. Albert, R. L. Albin, J. Alegre-Abarrategui, M. F. Aleo, M. Alirezaei, A. Almasan, M. Almonte-Becerril, A. Amano, R. Amaravadi, S. Amarnath, A. O. Amer, N. AndrieuAbadie, V. Anantharam, et al., Autophagy 2012, 8, 445-544.

12 C. H. Jung, S. H. Ro, J. Cao, N. M. Otto and D. H. Kim, FEBS Lett. 2010, 584, 12871295.

13 C. Vezina, A. Kudelski and S. N. Sehgal, J. Antibiot. 1975, 28, 721-726.

14 D. Benjamin, M. Colombi, C. Moroni and M. N. Hall, Nat. Rev. Drug Discov. 2011, 10, 868-880.

15 J. Choi, J. Chen, S. L. Schreiber and J. Clardy, Science 1996, 273, 239-242.

16 L. A. Banaszynski, C. W. Liu and T. J. Wandless, J. Am. Chem. Soc. 2005, 127, 4715-4721.

17 R. T. Abraham, J. J. Gibbons and E. I. Graziani in Chemistry and Pharmacology of Rapamycin and Its derivatives, Vol. XXVII Elsevier, 2010.

18 B. Boland, A. Kumar, S. Lee, F. M. Platt, J. Wegiel, W. H. Yu and R. A. Nixon, J. Neurosci. 2008, 28, 6926-6937.

19 J. Zhang, P. L. Yang and N. S. Gray, Nat. Rev. Cancer 2009, 9, 28-39.

20 R. Marone, V. Cmiljanovic, B. Giese and M. P. Wymann, Biochim. Biophys. Acta 2008, 1784, 159-185.

21 M. Hayakawa, H. Kaizawa, H. Moritomo, T. Koizumi, T. Ohishi, M. Yamano, M. Okada, M. Ohta, S. Tsukamoto, F. I. Raynaud, P. Workman, M. D. Waterfield and P. Parker, Bioorg. Med. Chem. Lett. 2007, 17, 2438-2442; M. Hayakawa, H. Kaizawa, H. Moritomo, T. Koizumi, T. Ohishi, M. Okada, M. Ohta, S. Tsukamoto, P. Parker, P. Workman and M. Waterfield, Bioorg. Med. Chem. 2006, 14, 6847-6858.

22 Z. A. Knight, B. Gonzalez, M. E. Feldman, E. R. Zunder, D. D. Goldenberg, 0. Williams, R. Loewith, D. Stokoe, A. Balla, B. Toth, T. Balla, W. A. Weiss, R. L. Williams and K. M. Shokat, Cell 2006, 125, 733-747.

23 F. I. Raynaud, S. Eccles, P. A. Clarke, A. Hayes, B. Nutley, S. Alix, A. Henley, F. DiStefano, Z. Ahmad, S. Guillard, L. M. Bjerke, L. Kelland, M. Valenti, L. Patterson, S. 
Gowan, A. de Haven Brandon, M. Hayakawa, H. Kaizawa, T. Koizumi, T. Ohishi, S. Patel, N. Saghir, P. Parker, M. Waterfield and P. Workman, Cancer Res. 2007, 67, 5840-5850.

24 Q. W. Fan, C. Cheng, C. Hackett, M. Feldman, B. T. Houseman, T. Nicolaides, D. Haas-Kogan, C. D. James, S. A. Oakes, J. Debnath, K. M. Shokat and W. A. Weiss, Science signaling 2010, 3, ra81.

25 H. Yang, D. G. Rudge, J. D. Koos, B. Vaidialingam, H. J. Yang and N. P. Pavletich, Nature 2013, 497, 217-223.

26 F. I. Raynaud, S. A. Eccles, S. Patel, S. Alix, G. Box, I. Chuckowree, A. Folkes, S. Gowan, A. De Haven Brandon, F. Di Stefano, A. Hayes, A. T. Henley, L. Lensun, G. Pergl-Wilson, A. Robson, N. Saghir, A. Zhyvoloup, E. McDonald, P. Sheldrake, S. Shuttleworth, M. Valenti, N. C. Wan, P. A. Clarke and P. Workman, Mol. Cancer Ther. 2009, 8, 1725-1738.

27 A. J. Folkes, K. Ahmadi, W. K. Alderton, S. Alix, S. J. Baker, G. Box, I. S. Chuckowree, P. A. Clarke, P. Depledge, S. A. Eccles, L. S. Friedman, A. Hayes, T. C. Hancox, A. Kugendradas, L. Lensun, P. Moore, A. G. Olivero, J. Pang, S. Patel, G. H. Pergl-Wilson, F. I. Raynaud, A. Robson, N. Saghir, L. Salphati, S. Sohal, M. H. Ultsch, M. Valenti, H. J. Wallweber, N. C. Wan, C. Wiesmann, et al., J. Med. Chem. 2008, 51, 5522-5532.

28 P. Workman, P. A. Clarke, F. I. Raynaud and R. L. van Montfort, Cancer Res. 2010, 70, 2146-2157.

29 D. P. Sutherlin, L. Bao, M. Berry, G. Castanedo, I. Chuckowree, J. Dotson, A. Folks, L. Friedman, R. Goldsmith, J. Gunzner, T. Heffron, J. Lesnick, C. Lewis, S. Mathieu, J. Murray, J. Nonomiya, J. Pang, N. Pegg, W. W. Prior, L. Rouge, L. Salphati, D. Sampath, Q. Tian, V. Tsui, N. C. Wan, S. Wang, B. Wei, C. Wiesmann, P. Wu, B. Y. Zhu, et al., J. Med. Chem. 2011, 54, 7579-7587.

30 Y. Zhang, D. Xue, X. Wang, M. Lu, B. Gao and X. Qiao, Mol. Med. Rep. 2014, 9, 8390.

31 S. J. Baker, P. J. Goldsmith, T. C. Hancox, N. A. Pegg, S. Price, S. P. Shuttleworth and S. Sohal, PCT Int. Appl., 2007122410, 01 Nov 2007.

32 F. Stauffer, S. M. Maira, P. Furet and C. Garcia-Echeverria, Bioorg. Med. Chem. Lett. 2008, 18, 1027-1030.

33 T. J. Liu, D. Koul, T. LaFortune, N. Tiao, R. J. Shen, S. M. Maira, C. Garcia-Echevrria and W. K. Yung, Mol. Cancer Ther. 2009, 8, 2204-2210.

34 S. M. Maira, F. Stauffer, J. Brueggen, P. Furet, C. Schnell, C. Fritsch, S. Brachmann, P. Chene, A. De Pover, K. Schoemaker, D. Fabbro, D. Gabriel, M. Simonen, L. Murphy, P. Finan, W. Sellers and C. Garcia-Echeverria, Mol. Cancer Ther. 2008, 7, 1851-1863. 
35 K. Y. Chang, S. Y. Tsai, C. M. Wu, C. J. Yen, B. F. Chuang and J. Y. Chang, Clin. Cancer. Res. 2011, 17, 7116-7126; W. J. Wang, L. M. Long, N. Yang, Q. Q. Zhang, W. J. Ji, J. H. Zhao, Z. H. Qin, Z. Wang, G. Chen and Z. Q. Liang, Acta Pharmacol. Sin. 2013, 34, 681-690; J. R. Li, C. L. Cheng, C. R. Yang, Y. C. Ou, M. J. Wu and J. L. Ko, Toxicol. Lett. 2013, 220, 267-276; S. Yang, X. Xiao, X. Meng and K. K. Leslie, PloS one 2011, 6, e26343.

36 G. B. Bachman, D. E. Welton and et al., J. Am. Chem. Soc. 1947, 69, 365-371.

37 F. Stowasser, M. Bänziger and S. D. Garad, PCT Int. Appl. (2008), WO 2008064093 A2 20080529.

38 O. K. Mirzoeva, B. Hann, Y. K. Hom, J. Debnath, D. Aftab, K. Shokat and W. M. Korn, J. Mod. Med. 2011, 89, 877-889.

39 S. Saiki, Y. Sasazawa, Y. Imamichi, S. Kawajiri, T. Fujimaki, I. Tanida, H. Kobayashi, F. Sato, S. Sato, K. Ishikawa, M. Imoto and N. Hattori, Autophagy 2011, 7, 176-187.

40 V. Wanke, E. Cameroni, A. Uotila, M. Piccolis, J. Urban, R. Loewith and C. De Virgilio, Mol. Microbiol. 2008, 69, 277-285.

41 T. Saurat, F. Buron, N. Rodrigues, M. L. de Tauzia, L. Colliandre, S. Bourg, P. Bonnet, G. Guillaumet, M. Akssira, A. Corlu, C. Guillouzo, P. Berthier, P. Rio, M. L. Jourdan, H. Benedetti and S. Routier, J. Med. Chem. 2014, 57, 613-631.

42 D. A. Fruman and C. Rommel, Nat. Rev. Drug Discov. 2014, 13, 140-156.

43 H. Y. Nam, M. W. Han, H. W. Chang, Y. S. Lee, M. Lee, H. J. Lee, B. W. Lee, H. J. Lee, K. E. Lee, M. K. Jung, H. Jeon, S. H. Choi, N. H. Park, S. Y. Kim and S. W. Kim, Cancer Res. 2013, 73, 4267-4277.

44 B. Apsel, J. A. Blair, B. Gonzalez, T. M. Nazif, M. E. Feldman, B. Aizenstein, R. Hoffman, R. L. Williams, K. M. Shokat and Z. A. Knight, Nat. Chem. Biol. 2008, 4, 691699.

45 M. E. Feldman, B. Apsel, A. Uotila, R. Loewith, Z. A. Knight, D. Ruggero and K. M. Shokat, PLoS Biol. 2009, 7, e38.

46 Q. Liu, J. W. Chang, J. Wang, S. A. Kang, C. C. Thoreen, A. Markhard, W. Hur, J. Zhang, T. Sim, D. M. Sabatini and N. S. Gray, J. Med. Chem. 2010, 53, 7146-7155.

47 C. C. Thoreen, S. A. Kang, J. W. Chang, Q. Liu, J. Zhang, Y. Gao, L. J. Reichling, T. Sim, D. M. Sabatini and N. S. Gray, J. Biol. Chem. 2009, 284, 8023-8032.

48 J. Zhou, S. H. Tan, V. Nicolas, C. Bauvy, N. D. Yang, J. B. Zhang, Y. Xue, P. Codogno and H. M. Shen, Cell Res. 2013, 23, 508-523. 
49 Q. Liu, J. Wang, S. A. Kang, C. C. Thoreen, W. Hur, T. Ahmed, D. M. Sabatini and N. S. Gray, J. Med. Chem. 2011, 54, 1473-1480.

50 Q. Liu, C. Xu, S. Kirubakaran, X. Zhang, W. Hur, Y. Liu, N. P. Kwiatkowski, J. Wang, K. D. Westover, P. Gao, D. Ercan, M. Niepel, C. C. Thoreen, S. A. Kang, M. P. Patricelli, Y. Wang, T. Tupper, A. Altabef, H. Kawamura, K. D. Held, D. M. Chou, S. J. Elledge, P. A. Janne, K. K. Wong, D. M. Sabatini and N. S. Gray, Cancer Res. 2013, 73, 25742586.

51 J. M. Garcia-Martinez, J. Moran, R. G. Clarke, A. Gray, S. C. Cosulich, C. M. Chresta and D. R. Alessi, Biochem. J. 2009, 421, 29-42; K. Malagu, H. Duggan, K. Menear, M. Hummersone, S. Gomez, C. Bailey, P. Edwards, J. Drzewiecki, F. Leroux, M. J. Quesada, G. Hermann, S. Maine, C. A. Molyneaux, A. Le Gall, J. Pullen, I. Hickson, L. Smith, S. Maguire, N. Martin, G. Smith and M. Pass, Bioorg. Med. Chem. Lett. 2009, 19, 5950-5953.

52 C. M. Chresta, B. R. Davies, I. Hickson, T. Harding, S. Cosulich, S. E. Critchlow, J. P. Vincent, R. Ellston, D. Jones, P. Sini, D. James, Z. Howard, P. Dudley, G. Hughes, L. Smith, S. Maguire, M. Hummersone, K. Malagu, K. Menear, R. Jenkins, M. Jacobsen, G. C. Smith, S. Guichard and M. Pass, Cancer Res. 2010, 70, 288-298.

53 H. Z. Huo, Z. Y. Zhou, B. Wang, J. Qin, W. Y. Liu and Y. Gu, Biochem. Biophys. Res. Commun. 2014, 443, 406-412.

54 A. Roscic, B. Baldo, C. Crochemore, D. Marcellin and P. Paganetti, J. Neurochem. 2011, 119, 398-407.

55 K. Yu, L. Toral-Barza, C. Shi, W. G. Zhang, J. Lucas, B. Shor, J. Kim, J. Verheijen, K. Curran, D. J. Malwitz, D. C. Cole, J. Ellingboe, S. Ayral-Kaloustian, T. S. Mansour, J. J. Gibbons, R. T. Abraham, P. Nowak and A. Zask, Cancer Res. 2009, 69, 6232-6240; A. Zask, P. Nowak, J. Verheijen, K. J. Curran, J. Kaplan, D. Malwitz, M. G. Bursavich, D. C. Cole, S. Ayral-Kaloustian, K. Yu, D. J. Richard and M. Lefever, WO patent W008115974. 2008. .

56 B. Nyfeler, P. Bergman, E. Triantafellow, C. J. Wilson, Y. Zhu, B. Radetich, P. M. Finan, D. J. Klionsky and L. O. Murphy, Mol. Cell. Biol. 2011, 31, 2867-2876.

57 S. M. Chen, J. L. Liu, X. Wang, C. Liang, J. Ding and L. H. Meng, Biochem. Pharmacol. 2012, 83, 1183-1194.

58 J. J. Gills and P. A. Dennis, Curr. Oncol. Rep. 2009, 11, 102-110.

59 L. Fu, Y. A. Kim, X. Wang, X. Wu, P. Yue, S. Lonial, F. R. Khuri and S. Y. Sun, Cancer Res. 2009, 69, 8967-8976.

60 G. Viola, R. Bortolozzi, E. Hamel, S. Moro, P. Brun, I. Castagliuolo, M. G. Ferlin and G. Basso, Biochem. Pharmacol. 2012, 83, 16-26. 
61 K. N. Thimmaiah, J. B. Easton, G. S. Germain, C. L. Morton, S. Kamath, J. K. Buolamwini and P. J. Houghton, J. Biol. Chem. 2005, 280, 31924-31935.

62 A. S. Tsvetkov, J. Miller, M. Arrasate, J. S. Wong, M. A. Pleiss and S. Finkbeiner, Proc Natl Acad Sci U S A 2010, 107, 16982-16987.

63 M. W. Berchtold and A. Villalobo, Biochim. Biophys. Acta 2014, 1843, 398-435.

64 J. Kim, M. Kundu, B. Viollet and K. L. Guan, Nat. Cell Biol. 2011, 13, 132-141.

65 W. Y. Shi, D. Xiao, L. Wang, L. H. Dong, Z. X. Yan, Z. X. Shen, S. J. Chen, Y. Chen and W. L. Zhao, Cell death \& disease 2012, 3, e275.

66 V. N. Anisimov, L. M. Berstein, P. A. Egormin, T. S. Piskunova, I. G. Popovich, M. A. Zabezhinski, M. L. Tyndyk, M. V. Yurova, I. G. Kovalenko, T. E. Poroshina and A. V. Semenchenko, Cell Cycle 2008, 7, 2769-2773.

67 N. T. Hertz, A. Berthet, M. L. Sos, K. S. Thorn, A. L. Burlingame, K. Nakamura and K. M. Shokat, Cell 2013, 154, 737-747; M. S. Lopez, J. W. Choy, U. Peters, M. L. Sos, D. 0. Morgan and K. M. Shokat, J. Am. Chem. Soc. 2013, 135, 18153-18159.

68 A. D. Balgi, B. D. Fonseca, E. Donohue, T. C. F. Tsang, P. Lajoie, C. G. Proud, I. R. Nabi and M. Roberge, PloS one 2009, 4.

69 K. S. Song, J. S. Kim, E. J. Yun, Y. R. Kim, K. S. Seo, J. H. Park, Y. J. Jung, J. I. Park, G. R. Kweon, W. H. Yoon, K. Lim and B. D. Hwang, Autophagy 2008, 4, 650-658.

70 D. Kumar, S. Shankar and R. K. Srivastava, Mol. Cancer 2013, 12, 171.

71 B. D. Fonseca, G. H. Diering, M. A. Bidinosti, K. Dalal, T. Alain, A. D. Balgi, R. Forestieri, M. Nodwell, C. V. Rajadurai, C. Gunaratnam, A. R. Tee, F. Duong, R. J. Andersen, J. Orlowski, M. Numata, N. Sonenberg and M. Roberge, J. Biol. Chem. 2012, 287, 17530-17545.

72 J. Pan, E. Song, C. Cheng, M. H. Lee and S. C. Yeung, Autophagy 2009, 5, 129-131.

73 M. Salazar, A. Carracedo, I. J. Salanueva, S. Hernandez-Tiedra, M. Lorente, A. Egia, P. Vazquez, C. Blazquez, S. Torres, S. Garcia, J. Nowak, G. M. Fimia, M. Piacentini, F. Cecconi, P. P. Pandolfi, L. Gonzalez-Feria, J. L. Iovanna, M. Guzman, P. Boya and G. Velasco, J. Clin. Invest. 2009, 119, 1359-1372.

74 A. Bommareddy, E. R. Hahm, D. Xiao, A. A. Powolny, A. L. Fisher, Y. Jiang and S. V. Singh, Cancer Res. 2009, 69, 3704-3712.

75 J. F. Lin, T. F. Tsai, P. C. Liao, Y. H. Lin, Y. C. Lin, H. E. Chen, K. Y. Chou and T. I. Hwang, Carcinogenesis 2013, 34, 406-414. 
76 X. Liu, R. R. Chhipa, I. Nakano and B. Dasgupta, Mol. Cancer Ther. 2014; M. R. Pears, S. Codlin, R. L. Haines, I. J. White, R. J. Mortishire-Smith, S. E. Mole and J. L. Griffin, Mol Biosyst 2010, 6, 1093-1102.

77 S. Sarkar, E. O. Perlstein, S. Imarisio, S. Pineau, A. Cordenier, R. L. Maglathlin, J. A. Webster, T. A. Lewis, C. J. O'Kane, S. L. Schreiber and D. C. Rubinsztein, Nat. Chem. Biol. 2007, 3, 331-338.

78 S. Turcotte, D. A. Chan, P. D. Sutphin, M. P. Hay, W. A. Denny and A. J. Giaccia, Cancer Cell 2008, 14, 90-102.

79 M. P. Hay, S. Turcotte, J. U. Flanagan, M. Bonnet, D. A. Chan, P. D. Sutphin, P. Nguyen, A. J. Giaccia and W. A. Denny, J. Med. Chem. 2010, 53, 787-797.

80 S. B. Gibson, Methods Enzymol. 2013, 528, 217-235; M. B. Azad, Y. Chen and S. B. Gibson, Antioxid. Redox Signal. 2009, 11, 777-790.

81 L. U. Ling, K. B. Tan, H. Lin and G. N. Chiu, Cell death \& disease 2011, 2, e129.

82 F. Raffoul, C. Campla and M. Nanjundan, Autophagy 2010, 6, 955-957.

83 H. Miki, N. Uehara, A. Kimura, T. Sasaki, T. Yuri, K. Yoshizawa and A. Tsubura, Int. J. Oncol. 2012, 40, 1020-1028.

84 J. Li, R. Liu, Y. Lei, K. Wang, Q. C. Lau, N. Xie, S. Zhou, C. Nie, L. Chen, Y. Wei and C. Huang, Autophagy 2010, 6, 711-724.

85 L. Li, G. Ishdorj and S. B. Gibson, Free Radical Biol. Med. 2012, 53, 1399-1410.

86 V. Gagliostro, J. Casas, A. Caretti, J. L. Abad, L. Tagliavacca, R. Ghidoni, G. Fabrias and P. Signorelli, Int. J. Biochem. Cell Biol. 2012, 44, 2135-2143.

87 P. Signorelli, J. M. Munoz-Olaya, V. Gagliostro, J. Casas, R. Ghidoni and G. Fabrias, Cancer Lett. 2009, 282, 238-243.

88 S. Huang and F. A. Sinicrope, Autophagy 2010, 6, 256-269.

89 W. Zheng, J. Kollmeyer, H. Symolon, A. Momin, E. Munter, E. Wang, S. Kelly, J. C. Allegood, Y. Liu, Q. Peng, H. Ramaraju, M. C. Sullards, M. Cabot and A. H. Merrill, Biochim. Biophys. Acta : Biomembranes 2006, 1758, 1864-1884.

90 W. Jiang and B. Ogretmen, Biochim. Biophys. Acta 2013.

91 K. M. Schubert, M. P. Scheid and V. Duronio, J. Biol. Chem. 2000, 275, 1333013335.

92 F. Scarlatti, C. Bauvy, A. Ventruti, G. Sala, F. Cluzeaud, A. Vandewalle, R. Ghidoni and P. Codogno, J. Biol. Chem. 2004, 279, 18384-18391. 
93 R. D. Sentelle, C. E. Senkal, W. H. Jiang, S. Ponnusamy, S. Gencer, S. P. Selvam, V. K. Ramshesh, Y. K. Peterson, J. J. Lemasters, Z. M. Szulc, J. Bielawski and B. Ogretmen, Nat. Chem. Biol. 2012, 8, 831-838.

94 C. Dall'armi, K. A. Devereaux and G. Di Paolo, Curr. Biol. 2013, 23, R33-45.

95 S. Teres, V. Llado, M. Higuera, G. Barcelo-Coblijn, M. L. Martin, M. A. NogueraSalva, A. Marcilla-Etxenike, J. M. Garcia-Verdugo, M. Soriano-Navarro, C. Saus, U. Gomez-Pinedo, X. Busquets and P. V. Escriba, Proc Natl Acad Sci U S A 2012.

96 T. Hidvegi, M. Ewing, P. Hale, C. Dippold, C. Beckett, C. Kemp, N. Maurice, A. Mukherjee, C. Goldbach, S. Watkins, G. Michalopoulos and D. H. Perlmutter, Science 2010, 329, 229-232.

97 A. Williams, S. Sarkar, P. Cuddon, E. K. Ttofi, S. Saiki, F. H. Siddiqi, L. Jahreiss, A. Fleming, D. Pask, P. Goldsmith, C. J. O'Kane, R. A. Floto and D. C. Rubinsztein, Nat. Chem. Biol. 2008, 4, 295-305.

98 L. H. Zhang, J. Yu, H. L. Pan, P. Hu, Y. Hao, W. Q. Cai, H. Zhu, A. D. Yu, X. Xie, D. W. Ma and J. Y. Yuan, Proc Natl Acad Sci U S A 2007, 104, 19023-19028.

99 C. Rose, F. M. Menzies, M. Renna, A. Acevedo-Arozena, S. Corrochano, O. Sadiq, S. D. Brown and D. C. Rubinsztein, Hum. Mol. Genet. 2010, 19, 2144-2153.

100 P. F. Finn, N. T. Mesires, M. Vine and J. F. Dice, Autophagy 2005, 1, 141-145.

101 J. Anguiano, T. P. Garner, M. Mahalingam, B. C. Das, E. Gavathiotis and A. M. Cuervo, Nat. Chem. Biol. 2013, 9, 374-382.

102 S. Kaushik, U. Bandyopadhyay, S. Sridhar, R. Kiffin, M. Martinez-Vicente, M. Kon, S. J. Orenstein, E. Wong and A. M. Cuervo, J. Cell Sci. 2011, 124, 495-499.

103 E. F. Blommaart, U. Krause, J. P. Schellens, H. Vreeling-Sindelarova and A. J. Meijer, Eur. J. Biochem. 1997, 243, 240-246.

104 E. H. Walker, M. E. Pacold, O. Perisic, L. Stephens, P. T. Hawkins, M. P. Wymann and R. L. Williams, Mol. Cell 2000, 6, 909-919.

105 P. Wipf and R. J. Halter, Org. Biomol. Chem. 2005, 3, 2053-2061.

106 G. J. Brunn, J. Williams, C. Sabers, G. Wiederrecht, J. C. Lawrence, Jr. and R. T. Abraham, EMBO J. 1996, 15, 5256-5267.

107 J. R. Garlich, P. De, N. Dey, J. D. Su, X. Peng, A. Miller, R. Murali, Y. Lu, G. B. Mills, V. Kundra, H. K. Shu, Q. Peng and D. L. Durden, Cancer Res. 2008, 68, 206-215.

108 Y. T. Wu, H. L. Tan, G. H. Shui, C. Bauvy, Q. Huang, M. R. Wenk, C. N. Ong, P. Codogno and H. M. Shen, J. Biol. Chem. 2010, 285, 10850-10861. 
109 N. Jaber, Z. Dou, J. S. Chen, J. Catanzaro, Y. P. Jiang, L. M. Ballou, E. Selinger, X. Ouyang, R. Z. Lin, J. Zhang and W. X. Zong, Proc Natl Acad Sci U S A 2012, 109, 20032008.

110 S. Miller, B. Tavshanjian, A. Oleksy, O. Perisic, B. T. Houseman, K. M. Shokat and R. L. Williams, Science 2010, 327, 1638-1642.

111 V. W. Armstrong, N. H. Chishti and R. Ramage, Tetrahedron Lett. 1975, 16, 373.

112 I. Hickson, Y. Zhao, C. J. Richardson, S. J. Green, N. M. Martin, A. I. Orr, P. M. Reaper, S. P. Jackson, N. J. Curtin and G. C. Smith, Cancer Res. 2004, 64, 9152-9159.

113 G. Martiny-Baron, M. G. Kazanietz, H. Mischak, P. M. Blumberg, G. Kochs, H. Hug, D. Marme and C. Schachtele, J. Biol. Chem. 1993, 268, 9194-9197.

114 T. Farkas, M. Daugaard and M. Jaattela, J. Biol. Chem. 2011, 286, 38904-38912.

115 J. Liu, H. Xia, M. Kim, L. Xu, Y. Li, L. Zhang, Y. Cai, H. V. Norberg, T. Zhang, T. Furuya, M. Jin, Z. Zhu, H. Wang, J. Yu, Y. Li, Y. Hao, A. Choi, H. Ke, D. Ma and J. Yuan, Cell 2011, 147, 223-234.

116 Y. J. Choi, Y. J. Park, J. Y. Park, H. O. Jeong, D. H. Kim, Y. M. Ha, J. M. Kim, Y. M. Song, H. S. Heo, B. P. Yu, P. Chun, H. R. Moon and H. Y. Chung, PloS one 2012, 7, e43418.

117 A. Agarwal, K. Srivastava, S. K. Puri and P. M. Chauhan, Bioorg. Med. Chem. Lett. 2005, 15, 531-533.

118 N. Mizushima, T. Yoshimori and Y. Ohsumi, Annu. Rev. Cell. Dev. Biol. 2011, 27, 107-132; C. A. Lamb, T. Yoshimori and S. A. Tooze, Nat. Rev. Mol. Cell Biol. 2013, 14, 759-774.

119 A. Yang, Y. Li, S. Pantoom, G. Triola and Y. W. Wu, ChemBioChem 2013, 14, 1296-1300.

120 C. W. Shu, C. Madiraju, D. Zhai, K. Welsh, P. Diaz, E. Sergienko, R. Sano and J. C. Reed, J. Biomol. Screen. 2011, 16, 174-182.

121 T. Johansen and T. Lamark, Autophagy 2011, 7, 279-296.

122 P. Wild, D. G. McEwan and I. Dikic, J. Cell Sci. 2014, 127, 3-9.

123 A. U. Hain, R. R. Weltzer, H. Hammond, B. Jayabalasingham, R. R. Dinglasan, D. R. Graham, D. R. Colquhoun, I. Coppens and J. Bosch, J. Struct. Biol. 2012, 180, 551562.

124 M. G. Gutierrez, D. B. Munafo, W. Beron and M. I. Colombo, J. Cell Sci. 2004, 117, 2687-2697. 
125 M. Tamai, K. Matsumoto, S. Omura, I. Koyama, Y. Ozawa and K. Hanada, J. Pharmacobio. Dynam. 1986, 9, 672-677; Y. Shoji-Kasai, M. Senshu, S. Iwashita and K. Imahori, Proc Natl Acad Sci U S A 1988, 85, 146-150.

126 D. H. Rich, M. S. Bernatowicz, N. S. Agarwal, M. Kawai, F. G. Salituro and P. G. Schmidt, Biochemistry 1985, 24, 3165-3173.

127 T. Yoshimori, A. Yamamoto, Y. Moriyama, M. Futai and Y. Tashiro, J. Biol. Chem. 1991, 266, 17707-17712.

128 A. Yamamoto, Y. Tagawa, T. Yoshimori, Y. Moriyama, R. Masaki and Y. Tashiro, Cell Struct. Funct. 1998, 23, 33-42.

129 D. J. Klionsky, Z. Elazar, P. O. Seglen and D. C. Rubinsztein, Autophagy 2008, 4, 849-850.

130 F. Marceau, M. T. Bawolak, R. Lodge, J. Bouthillier, A. Gagne-Henley, R. C. Gaudreault and G. Morissette, Toxicol. Appl. Pharmacol. 2012, 259, 1-12.

131 R. K. Amaravadi, J. Lippincott-Schwartz, X. M. Yin, W. A. Weiss, N. Takebe, W. Timmer, R. S. DiPaola, M. T. Lotze and E. White, Clin. Cancer. Res. 2011, 17, 654666.

132 H. Maes, A. Kuchnio, A. Peric, S. Moens, K. Nys, K. De Bock, A. Quaegebeur, S. Schoors, M. Georgiadou, J. Wouters, S. Vinckier, H. Vankelecom, M. Garmyn, A. C. Vion, F. Radtke, C. Boulanger, H. Gerhardt, E. Dejana, M. Dewerchin, B. Ghesquiere, W. Annaert, P. Agostinis and P. Carmeliet, Cancer Cell 2014, 26, 190-206.

133 D. J. Klionsky, Nat. Rev. Mol. Cell Biol. 2007, 8, 931-937. 